\title{
RESEARCH
}

Open Access

\section{The benefits of international volunteering in a low-resource setting: development of a core outcome set}

\author{
Natasha Tyler ${ }^{*}$ (D), John Chatwin ${ }^{1}$, Ged Byrne ${ }^{2}$, Jo Hart ${ }^{3}$ and Lucie Byrne-Davis ${ }^{3}$
}

\begin{abstract}
Background: Qualitative narrative analysis and case studies form the majority of the current peer-reviewed literature about the benefits of professional volunteering or international placements for healthcare professionals. These often describe generalised outcomes that are difficult to define or have multiple meanings (such as 'communication skills' or 'leadership') and are therefore difficult to measure. However, there is an interest from employers, professional groups and individual volunteers in generating metrics for monitoring personal and professional development of volunteers and comparing different volunteering experiences in terms of their impact on the volunteers. In this paper, we describe two studies in which we (a) consolidated qualitative research and individual accounts into a core outcome set and (b) tested the core outcome set in a large group of global health stakeholders.
\end{abstract}

Method: We conducted a systematic review and meta-synthesis of literature to extract outcomes of international placements and variables that may affect these outcomes. We presented these outcomes to 58 stakeholders in global health, employing a Delphi method to reach consensus about which were 'core' and which were likely to be developed through international volunteering.

Results: The systematic review of 55 papers generated 133 unique outcomes and 34 potential variables. One hundred fifty-six statements were then presented to the Delphi stakeholders, of which they agreed 116 were core to a wide variety of healthcare professional practice and likely to be developed through international experiences. The core outcomes (COs) were both negative and positive and included skills, knowledge, attitudes and outcomes for healthcare organisations.

Conclusions: We summarised existing literature and stakeholder opinion into a core outcome set of 116 items that are core to healthcare professional practice and likely to be developed through international experiences. We identified, in the literature, a set of variables that could affect learning outcomes. The core outcome set will be used in a future study to develop a psychometric assessment tool.

Keywords: Systematic review, Delphi, Core outcomes, International volunteering, International placements, Health professional education

\footnotetext{
* Correspondence: natasha.tyler@nottingham.ac.uk

'University of Nottingham, Nottingham, UK

Full list of author information is available at the end of the article
}

(c) The Author(s). 2018 Open Access This article is distributed under the terms of the Creative Commons Attribution 4.0 International License (http://creativecommons.org/licenses/by/4.0/), which permits unrestricted use, distribution, and reproduction in any medium, provided you give appropriate credit to the original author(s) and the source, provide a link to the Creative Commons license, and indicate if changes were made. The Creative Commons Public Domain Dedication waiver (http://creativecommons.org/publicdomain/zero/1.0/) applies to the data made available in this article, unless otherwise stated. 


\section{Background}

Volunteering, or temporarily working in low-resource settings, is often seen solely as a means of helping those in poorer economies [1]. Many professionals find it difficult to obtain support to volunteer and report lack of recognition upon return, which is disincentive to volunteerism [2]. Furthermore, health professionals that volunteer abroad predominantly do so using annual leave, rather than recognised study leave for continued professional development [3, 4]. The notion that those from high-income countries (HICs) are altruistically offering 'help' to those in low- and middle-income countries (LMICs) can also lead to a distortion of the partnership relationship between high- and low-income partners in health partnerships. The low-income partners can be seen as beneficiaries and the high-income partners seen as donors [5-7]. Furthermore, a tension often exists between UK healthcare professionals and local international staff, as the intentions or role of healthcare professionals and students is often not explicit to the teams with whom they are working. However, the donor-recipient relationship is becoming increasingly contested in recent literature and policy and mutual benefits realised $[8,9]$.

There is an imperative, therefore, to fully understand the learning outcomes that are possible for HIC health professionals working in low-resource settings and, in particular, to help recognise these activities as educational development $[2,3]$. Understanding 'what' is gained would allow specification of intended learning outcomes for training and continuing professional development and to make the gain for the HIC more explicit. Understanding under what circumstances learning outcomes occur would result in an understanding of how to maximise that gain.

Literature that explores what and how healthcare professionals learn from temporarily working or volunteering in a low-resource setting tends to report anecdotes or single reports, which provide a lower level of evidence $[4,10]$. Furthermore, benefits are detailed in broad categories, with 'leadership', 'communication' and 'cultural awareness' being frequently reported [3,11-13], with a focus on one of these skill sets in depth or a list of outcomes under umbrella terms, such as communication or leadership skills $[3,14]$. These broad labels make an assessment of the learning outcomes difficult as they might contain multiple underpinning knowledge, skills, practice and attitudes. Self-assessment of broad terms is not well associated with objective performance [15]; individuals struggle to assess themselves in relation to ambiguous or ill-defined traits [16, 17]. Specifying learning at this broad level means that the more granular levels remain unspecified. A higher-level group might contain a wide range of lower-level outcomes and might not contain others, which would reduce the content validity of an assessment.
Understanding the metrics of health professional volunteerism would have a significant impact on current continued professional development (CPD) policy because international experiences could be evidenced as beneficial to personal and professional development. Numerous policy documents about future health workforce highlight the importance of skills such as leadership, communication and adaptability $[18,19]$. Such skills have been described as key outcomes of international placements in LMICs, but have yet to be quantified to enable comparison with other learning opportunities [3].

In a systematic review of the evidence of the benefits to the United Kingdom of health partnership work, Jones et al. reported 40 individual benefits grouped within seven key domains (communication and teamwork, clinical skills, management skills, patient experience and dignity, policy, academic skills and personal satisfaction and interest). There were a number of features of this review that makes it insufficient for the purposes of measuring learning outcomes from international volunteering. Firstly, this review focused only on health partnerships, a specific type of health link, and not all types of volunteering or international placements. Secondly, the findings were categorised broadly, with the difficulties of broad measurement specified above. Thirdly, the professions in their search terms were only doctors and nurses. Finally, it did not extract factors that may affect learning outcomes. For the purpose of measurement, we needed to include literature from a broad range of experiences, extract outcomes at a granular level, include all healthcare staff groups and extract variables that may affect these outcomes.

The outcomes for health professionals are not always positive and the costs of international placements in literature have included health consequences, skills degradation and financial cost $[3,20,21]$, reputational, health and opportunity [3]. Research has explored the costs and benefits of international placements $[13,20,22]$ and barriers to volunteering, but no research has yet listed all reported negative outcome [23].

Many aspects of LMIC placements are different from working in a HIC. Relationships between outcomes and these aspects have been proposed, for example that individuals learnt from the opportunity to interact with more patients or conditions than in the United Kingdom $[10,24]$ and that longer stays may be more beneficial than shorter stays $[25,26]$. These variables have not been systematically reported.

This current paper presents two studies: a meta-synthesis and a Delphi. The meta-synthesis aimed to (a) detail the personal and professional development outcomes of international work, at a granular level, i.e. 'knowledge about procedures rarely conducted in the United Kingdom' (rather than at a too broad level, i.e. clinical skills or too specific level, i.e. experience conducting vesico-vaginal fistula 
surgery); (b) to report the variables that influence these personal and professional development outcomes; and (c) to explore if the review including all types of UK health professional placement and all cadres of staff found the same categories as the most recent review of Jones et al. [3]. The Delphi study aimed to gather consensus from those with knowledge and expertise in international health professional learning and development, to refine a set of agreed core outcomes.

\section{Method}

\section{Study 1: Meta-synthesis study design and sample}

The systematic review of peer-reviewed literature, published in academic journals, was conducted between September and November 2014. Inclusion criteria included that (1) participants must not be in receipt of their full UK salary (a stipend or living allowance was permissible), thus excluding those in permanent employment overseas; (2) health professionals or health professional students (students were included, as much research has been conducted about educational outcomes in students); (3) activities must be health-focused to ensure outcomes were related to clinical work; (4) some participants must have departed from the United Kingdom and be UK citizens (papers that included a partial UK sample were included); (5) some participants must only have travelled to a LMIC; and (6) the paper must reference something that is perceived as a benefit, cost or potential variable, (7) there were no date restrictions. Guidelines for inclusion were used to ensure consistency.

Each paper was screened by one team member (NT) to ensure that it met the inclusion criteria. A second team member (JC) independently checked the first $20 \%$ of the included papers to ensure agreement of implementation of inclusion criteria. This was then discussed in a meeting. Disagreements would have been resolved using discussion and refining inclusion criteria for greater specificity; however, the reviewers agreed on all of the papers for inclusion (Table 1).

\section{Data sources and study selection}

A standard set of terms were used to search 11 databases for peer-reviewed literature between the earliest date indexed and the time of the review. This included

\section{Table 1 Inclusion criteria}

\footnotetext{
The inclusion criteria for the systematic review were peer-reviewed literature, where:

1) Individuals are either volunteers (i.e. not in receipt of full salary) or students on international placements.

2) Activities have a health focus

3) The individuals must be from the UK travelling to a lower income or lower-middle income country

4) There is reference to (individual, institutional or national) benefits or costs or the variables that moderate/mediate outcomes

5) English Language only
}

five columns of synonyms relating to outcomes and variables, international volunteering placements, health professionals, the United Kingdom and LMICs (see Additional file 1). The databases were medical and generic databases: Cochrane Economic Evaluations, Health Management Information Consortium, Health Business Elite, Web of Knowledge/Social Sciences Citation Index, PsycINFO, CINAHL, AMED, International Bibliography of Social Sciences, Social Services Abstracts and Sociological Abstracts, Global Health and JSTOR.

The abstracts and titles of each result of the electronic database search were screened, papers that did not meet inclusion criteria were removed and retained papers were rescreened to confirm inclusion.

\section{Citation mapping}

Reference lists of all included papers were assessed. Any papers that were of relevance were assessed against the inclusion criteria.

\section{Quality assessment}

We chose to include papers that were peer-reviewed but did not present empirical findings; therefore, the Cochrane risk of bias tool was not applicable to this research [27]. We categorised the papers using a quality framework [28].

\section{Data extraction}

We took a thematic synthesis approach to data extraction [29], which consists of three stages: line-by-line coding of text, development of descriptive themes and generation of analytical themes. We did not undertake the third stage as our purpose was the extract outcomes as a low level and the third stage has been criticised for being open to the judgement of the researcher $[29,30]$.

Each study that met the inclusion criteria was read, and any text (related to variables or positive/negative outcomes, at an individual, national or institutional level) was coded according to both content (explicitly stated in the papers) and meaning (inferred by the researcher). Outcomes were defined as anything that happens to UK health professionals as a result of volunteering/international placements (at an individual, national or institutional level), both positive and negative. Variables were any factors that reported influence outcomes, both implicitly and explicitly.

Using Nvivo, a node was created at a ranked level for each component of descriptive theme. For example, the outcome experience conducting 'vesico-vaginal fistula surgery' was coded within the second-order theme of 'greater knowledge of procedures not used in the United Kingdom' within the higher-order theme of 'Increased awareness of and knowledge about conditions and procedures rarely encountered in the United Kingdom'. We decided that the lowest level of specificity would be 
applicable to all/most professions and generalisable across situations. As each paper was coded, the nodes were adapted, developed and generated. Two researchers (NT, JC) independently reviewed the first $20 \%$ of papers and then met to develop a coding framework together. There were no disagreements as we were not looking to categorise, but rather develop a matrix of emerging codes; therefore, any differences in extraction occurred only when one reviewer had overlooked an outcome cost or variable. The second reviewer verified the extraction of the data from a further $20 \%$ of papers.

\section{Study 2: Stakeholder Delphi Design}

We used the Delphi method, an iterative process of rounds in which data are collected and condensed into a group consensus [31]. A series of virtual questionnaires record participant's agreement with statements concerning a particular topic. Delphi is often used to develop COS in health research $[32,33]$. As we were creating a core outcome set, this stage of the process only included the outcomes extracted in study 1 ; variables were not included.

In round 1, we held a face-to-face discussion group with stakeholders to generate outcomes. Subsequent rounds were online (with paper version emailed if there were technical difficulties). Participants were asked to indicate to what extent they agreed or disagreed each outcome was a core outcome of international placements and volunteering.

\section{Participants}

Participants were people who were volunteering health professionals; coordinators of international health professional volunteers, responsible for intended learning outcomes (ILOs) for health professionals; coordinators of health partnerships; study health professional education and international development; educational commissioners and NHS stakeholders. Participants were recruited for an initial workshop from a global health network, to ensure that participants from each of the stakeholder groups were invited and represented. Non-attendees were invited to participate online. After this event, a snow-ball sampling technique was used to reach further stakeholders from each group for online rounds; participants were asked to recommend interested individuals.

\section{Instrumentation round 1: Stakeholder face-to-face discussion and pilot}

In order to generate a list of outcomes, any new data generated from round 1 was added to the existing coding framework (see Additional file 1). Outcomes were then generated by presenting the highest-order theme as the outcome and any relevant lower-order themes as examples within brackets to add context. We input outcomes from the meta-synthesis and any additional outcomes from round 1 of the Delphi, into the hosting software. We piloted round 2 with seven members of the research team, who commented on structure, grammar, wording, level of specificity and technical issues. With the addition of items from the Delphi round 1 and comments from the pilot (and separation of some outcomes into two unique outcomes), the 133 outcomes from the meta-synthesis were converted into a list comprising of 156 outcomes to go forward to round 2 .

\section{Rounds 2-4: The online rounds of the Delphi}

Two team members divided the 156 outcomes into three categories (see Table 2): knowledge, skills and attitudes $(n=115)$; organisational outcomes $(n=8)$; and negative outcomes $(n=33)$. Statements were presented alongside a 7-point Likert-type scale, regarding agreement as to whether each statement should be "considered a 'core outcome' of international placements that should be measured in a toolkit". The scale used the following numbers to represent agreement: 1 = strongly disagree, 2 = disagree, $3=$ slightly disagree, $4=$ no preference, $5=$ slightly agree and 6 = agree, 7 = strongly agree. For emphasis, the phrase 'core outcome' was presented in bold and the definition was repeated in numerous emails, instructions and synopsis. A core outcome was defined in the following way:

A core outcome is something that is common, important and applicable across a wide range of settings. It can be a benefit or cost, but it must be something that would be more likely to happen to an individual on international placement rather than somebody working in the UK.

For each round, participants had 14 days to respond. Email reminders were sent to invitees frequently. However, as the initial questionnaire was particularly long, some participants requested an extension of the deadline by 10 days and 2 days at round 3 . In round 4 , participants who had not responded in round 3 (but had in round 2) were invited to re-join the study; many stakeholders worked internationally and had limited internet access at certain periods. In round 4, the expressions of some statements were changed in light of the comments from previous rounds to improve clarity.

Table 2 The three questions presented to stakeholders

1) KNOWLEDGE, SKILLS AND ATTITUDES: to what extent do you believe the following is a CORE outcome of international placements (that should be measured in a toolkit)?

2) ORGANISATIONAL OUTCOMES: to what extent do you believe the following is a CORE outcome of international placements (that should be measured in a toolkit)?

3) NEGATIVE OUTCOMES: To what extent do you believe the following is a CORE outcome of international placements (that should be measured in a toolkit)? 
The statements with at least $70 \%$ consensus in the previous round were retained and not re-presented to the group. Therefore, by round 4, a much smaller group of non-consensus statements were presented. In rounds 3 and 4, participants were asked to use the same Likert scale and reconsider their answers from the previous round (displayed) in light of the group median and any anonymised comment gathered in the previous round.

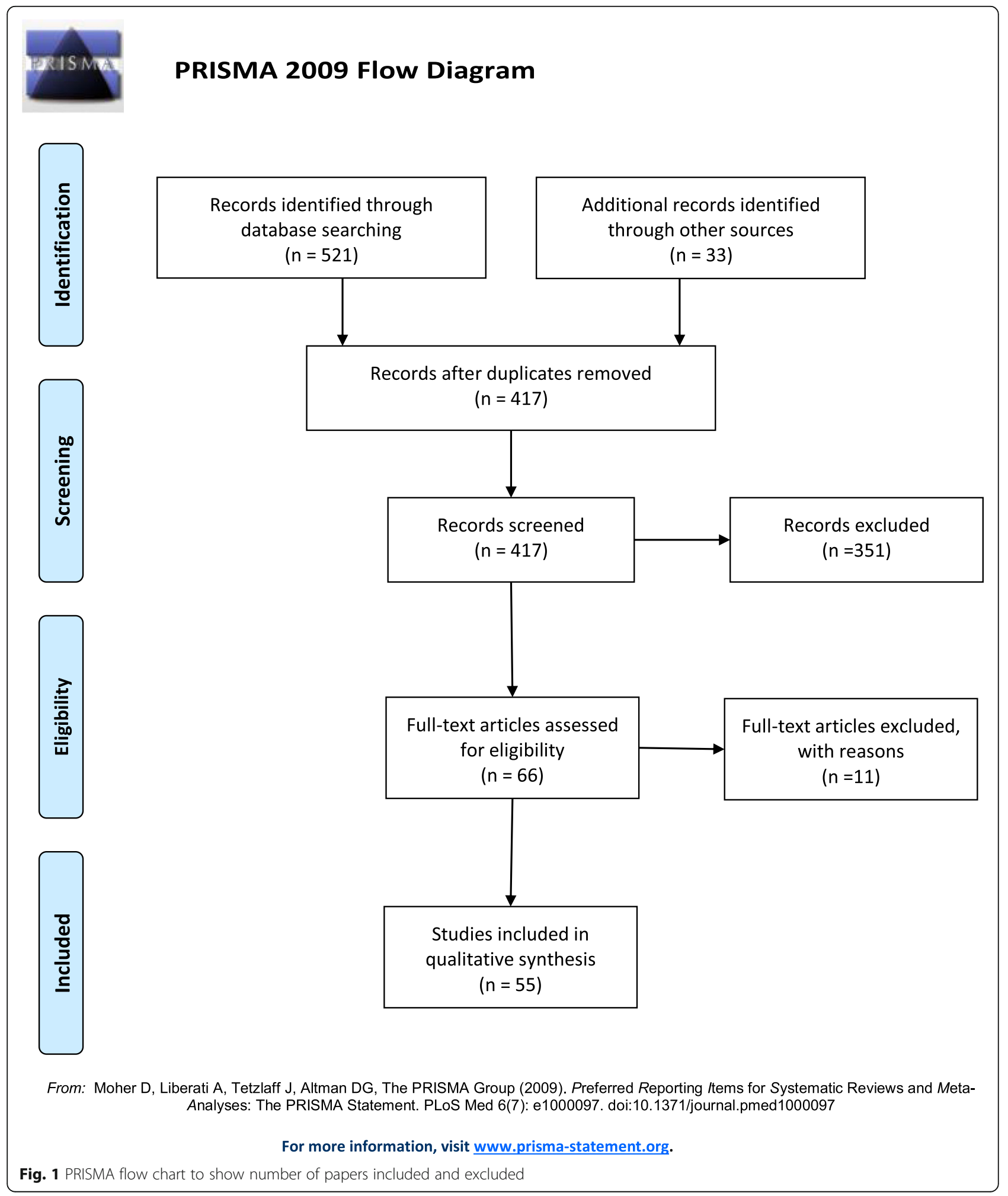




\section{Results}

\section{Study 1: Meta-synthesis}

\section{Data sources}

The search of the electronic databases generated 521 hits including duplicates, i.e. 384 unique papers. Twenty-two papers met inclusion criteria. Citation mapping revealed a further 33 papers which were included. Therefore, the total number of papers from which data was extracted was 55 . The main reasons for exclusions of papers were (1) not concerning the subject of interest, (2) non-British populations, (3) no health focus, (4) only placements in HIC, 5) only including paid/permanent staff and (6) reporting no benefits, outcomes or costs.

No papers included fell within the top two quality categories proposed by Benzies et al.: randomised controlled trials [28]. Some papers included qualitative or quantitative data $(23 / 55,42 \%)$, but the majority of papers reported no primary data.

Positive outcomes were extracted from 96\% (53/55) of the papers, whilst negative outcomes were extracted from only $49 \%$ (27/55). Potential variables that could affect these outcomes were extracted from $90.91 \%$ (50/55) of papers. None of the papers explicitly reported or explored how variables were thought to affect outcomes (Fig. 1 and Table 3).

\section{Extracted outcomes}

We found 133 unique outcomes, including 28 negative outcomes. The outcomes extracted could be categorised within NHS professional development terminology; there were 24 items about knowledge, 44 about skills and 20 about attitudes [34]. Six were organisational benefits and 29 negative; 10 were categorised as 'other'. Organisational outcomes were deliberately separated, as organisation-specific outcomes were identified in addition to the general positive effect of staff with developed knowledge, skills and attitudes. Only 29 (22\%) of the outcomes stated in the literature were negative, suggesting an overall positive attitude towards international placements from the authors (Fig. 2 and Tables 4 and 5).

\section{Study 2: Delphi Participants}

Fifty-one participants attended the round 1 workshop. Invitations were sent to 259 participants for the online Delphi, and 78 (30\%) accepted. Once enrolled in the study, response rates remained high: round $2, n=58 / 78(74 \%)$; round 3, $n=49$ (63\%); and round $4, n=45$ (58\%). More than half of the participants were involved in global health policy, and one third of the participants had volunteered.

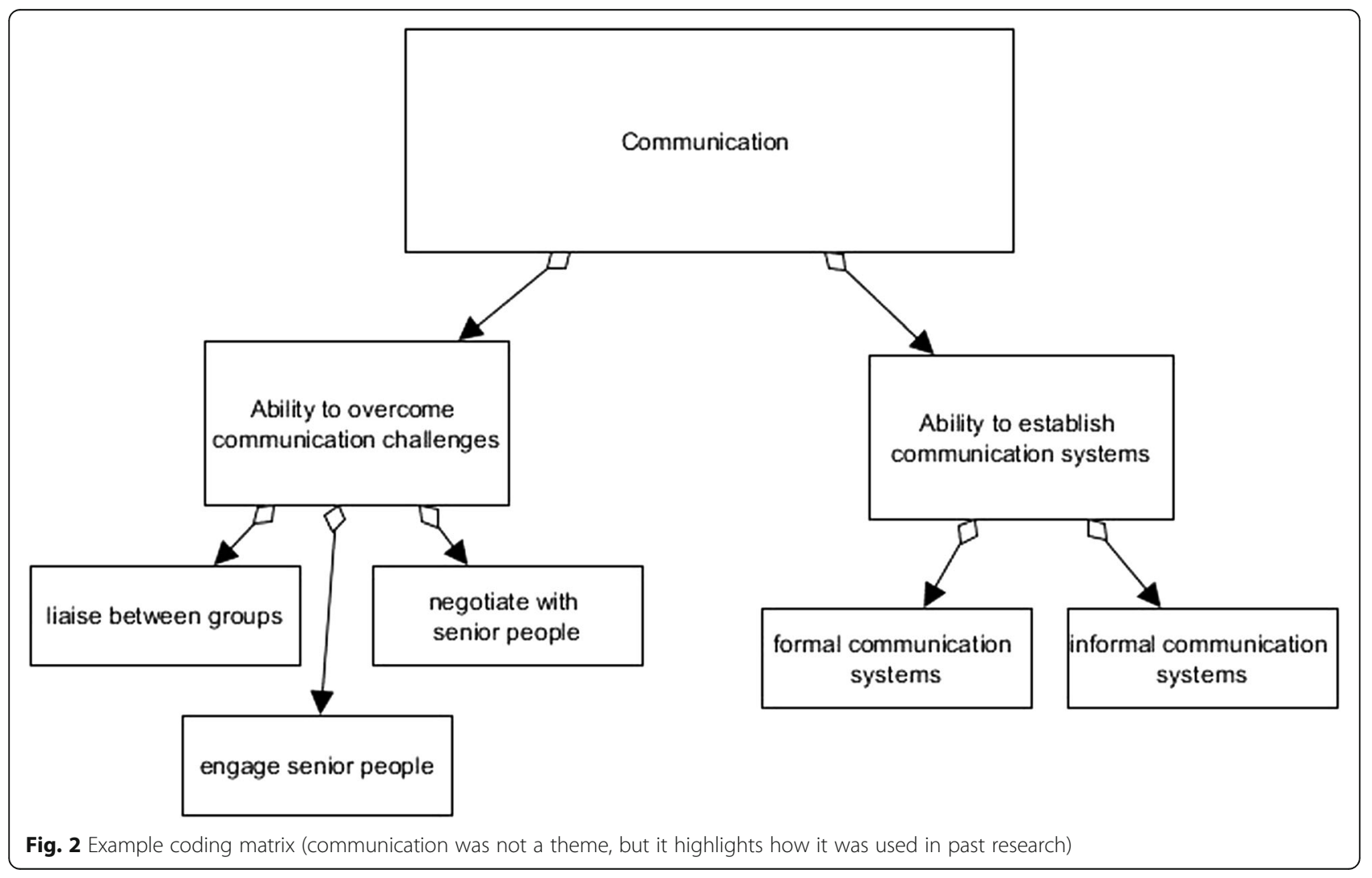


Table 3 Factors which influence outcomes

\begin{tabular}{|c|c|c|}
\hline Higher order themes & Lower order Components & Examples from data \\
\hline \multicolumn{3}{|l|}{ External Variables } \\
\hline Ethics & $\begin{array}{l}\text { Are local patients informed of } \\
\text { the risk? } \\
\text { Corporate and social } \\
\text { responsibility } \\
\text { Do patients come first? } \\
\text { Levels of standards } \\
\text { Health and Safety }\end{array}$ & $\begin{array}{l}\text { "For example, it was not uncommon at first for an anaesthesiologist to encounter } \\
\text { a complex paediatric patient having major surgery in the operating theatre where } \\
\text { she was expected to proceed with anaesthesia without question and without } \\
\text { preparation of adequate drugs or equipment." (Kinnear, 2013) } \\
\text { "I just think the really important thing in the drawbacks is the health and safety } \\
\text { issues-l think we have that as the biggest drawback-on both sides really; the } \\
\text { volunteers and the patients in host countries" (Workshop Participant) }\end{array}$ \\
\hline Funding & $\begin{array}{l}\text { Consistency of funding for } \\
\text { project } \\
\text { Finance plan for project } \\
\text { Funding from a charity or grant } \\
\text { Volunteer funded by sending } \\
\text { organisation } \\
\text { Volunteer fundraising } \\
\text { Support of a health link } \\
\text { partnership } \\
\text { Self-funding } \\
\text { Specific funding for training }\end{array}$ & $\begin{array}{l}\text { "The period of external funding is drawing to a close and the link needs more } \\
\text { regular and predictable funding to ensure sustainability." (Baillie, 2009) } \\
\text { "All international experiences are financed by the students either by assistance } \\
\text { from grant awarding bodies, fund raising activities or personal finance." } \\
\text { (Thompson, 2000) }\end{array}$ \\
\hline $\begin{array}{l}\text { Decision of host countries } \\
\text { needs }\end{array}$ & $\begin{array}{l}\text { Needs Assessment by both } \\
\text { parties } \\
\text { High income party decides } \\
\text { Host country decides }\end{array}$ & $\begin{array}{l}\text { "In South Africa, for example, the government tries to fill all clinical posts with local } \\
\text { doctors. Only when a post has not been filled by a local doctor does the } \\
\text { government seek external applications for which UK GP trainees can apply." } \\
\text { (Kiernan, 2014) }\end{array}$ \\
\hline Healthcare facility factors & $\begin{array}{l}\text { Does the environment favour } \\
\text { flexibility } \\
\text { Does management allow } \\
\text { people to become multi-skilled } \\
\text { Level of organisational support } \\
\text { Use of specific activities/ } \\
\text { sessions for learning } \\
\text { Volunteer exposure to } \\
\text { numerous systems } \\
\text { Opportunities for exposure to } \\
\text { culture outside of hospital } \\
\text { Differences in protocols } \\
\text { Licensing and professional } \\
\text { regulations } \\
\text { Level of corruption } \\
\text { Are volunteer skills best } \\
\text { utilised? } \\
\text { Encouragement and motivation } \\
\text { of volunteers } \\
\text { Financial and human resources } \\
\text { Criticism of project/volunteers } \\
\text { Mobility of local staff } \\
\text { Existence of local role models } \\
\text { Number of times volunteers } \\
\text { and local professionals engage }\end{array}$ & $\begin{array}{l}\text { "This support is, by necessity, mostly provided by the host supervisor, and home } \\
\text { medical schools in effect delegate their duty of care to the host." (Lumb, 2014) } \\
\text { "Students should be exposed to a variety of nursing experiences within the host } \\
\text { country. This would give them a broad spectrum for comparisons between } \\
\text { cultures, nursing practice and health care delivery in those cultures" (Button, 2005) }\end{array}$ \\
\hline $\begin{array}{l}\text { Benefits for host } \\
\text { organisation }\end{array}$ & $\begin{array}{l}\text { Donations } \\
\text { Material/financial benefits } \\
\text { Payment for supervision }\end{array}$ & $\begin{array}{l}\text { "In order to transform a process favouring the trainee into an equitable exchange, } \\
\text { each trainee must recognise the need for reciprocity when a community } \\
\text { contributes to his or her education. This might manifest through the provision of } \\
\text { resources, such as books and surgical supplies, of teaching and new ideas, or of } \\
\text { money, which could be reallocated to meet local need." (Banatlava, 1998) }\end{array}$ \\
\hline Income of host country & $\begin{array}{l}\text { Low } \\
\text { Middle } \\
\text { High }\end{array}$ & $\begin{array}{l}\text { "They therefore concluded that there was no significant difference in level of } \\
\text { knowledge and skill gained by going to a developed or developing country" } \\
\text { (Button, 2005) }\end{array}$ \\
\hline $\begin{array}{l}\text { Commitment of local staff } \\
\text { to project }\end{array}$ & $\begin{array}{l}\text { Staff time pressures } \\
\text { Empowerment of local staff } \\
\text { Involvement of hospital leaders } \\
\text { Project use local experts } \\
\text { Local perceptions of volunteers } \\
\text { Value of volunteer opinions }\end{array}$ & $\begin{array}{l}\text { "It was reported that some overseas staff are wary of offering constructive criticism, } \\
\text { not wishing to appear ungrateful. There is a move among many links to address } \\
\text { this problem through structured appraisal and evaluation for each visit. One had } \\
\text { begun to use anonymous feedback forms to learn from visits and improve the } \\
\text { quality and effectiveness of health links." (Baguley, 2006) } \\
\text { "As this host explains, two prominent negative aspects are insufficient input and } \\
\text { time" (Pearson, 2014) }\end{array}$ \\
\hline
\end{tabular}


Table 3 Factors which influence outcomes (Continued)

\begin{tabular}{ll}
\hline Higher order themes & Lower order Components \\
\hline Difference between host & Cultural distance between host \\
and origin country & and origin country \\
& Level of cultural immersion \\
& Severity of communication \\
difficulties & Shared values and cultural fit \\
& Accreditation \\
NHS and UK Factors & Existence of returner schemes \\
& Bureaucracy \\
& Political Climate in UK \\
& Recognition of benefits by \\
& NHS/UK organisation \\
& Trust, deaneries and PCT's \\
& support and influence \\
& Support of UK colleagues
\end{tabular}

Relationship between host Dependence on one-another and sending organisation Quality of communication Collaboration Differing expectations Equality of input Ground rules and protocol How the link is set up Multi-departmental partnerships Registered links i.e. THET Sensitivity to local contexts Sustainability of relationship Length of relationship Uni-professional or multidisciplinary

Level of supervision and support

Existence of other similar project in areas

Focus of project

Practical Factors

Mentor in UK

Support in UK

Supervision from western staff residing in host country Linking of senior and junior volunteers Supervision from local people Support structure in host country

Access to HR

Over-crowding of volunteers in hospitals

Support from others volunteers in another project

Agreement of focus Focus on mutual benefit Alignment of project with host country health plans Capacity building focus

Service delivery focus Developmental focus Sustainability focus Training focus

Travel

Accommodation Use of travel agent Documentation

Structure of the programme Aims developed by volunteers themselves Informed by other similar projects

Informed by literature Coercion

Continuation of project by

other volunteers

Involvement of local
Examples from data

"The greater the cultural differences of the international placement, the greater the impact." (Thompson, 2000)

"One of the main weaknesses has been difficulties with communication between the two partners in the link, exacerbated by problems with access to email in Uganda, intermittent exchange visits and an excessive reliance on communication through the two link coordinators. "(Longstaff, 2012)

"This placement is recognized by the (UK) Royal College of Anaesthetists to count towards training, and these trainees will all have completed their Royal College examinations before the trip." (Button 2005)

"Many forward-thinking NHS trusts actively support relationships with overseas organisations but barriers remain." (Dean, 2013)

"Links are not properly established until a visit has given collaborators time to become familiar with each other and to plan the first year, at least, of their work together." (Parry, 1998)

"Links forged as trainees on these initial UROLINK visits have often been

strengthened, and centres where these trainees have become consultants are now 'twinning' to continue the two-way exchange of experience." (Gujral, 2002)

"less support from organisational structure, developed skills as a result' (workshop participant)

'the supervision styles of host supervisors as the major challenges faced '(Horton, 2009)

"specialises in delivering high-quality primary health care in very hard to reach communities, where government service provision is non-existent and where there are very few other NGO projects" (Nunns 2011)

'For IMV placements to work, both host and volunteer need to have realistic goals and a common understanding of the aims of the placement." (Elnaway, 2013)

The most commonly-reported roles overall were clinical service delivery in a nonemergency setting' (Seo, 2012)

some students plan their electives in groups, all travelling to a particular destination. This process often involves students planning a travel experience rather than a learning experience. (Miranda, 2005)

'undertaking project work, particularly if beneficial to the host.' (Lumb, 2014) "It may have been helpful to obtain more input from similar programs at an earlier stage of planning, and it would be helpful in the future to establish formal links between programs or a forum for discussion" (Kinnear, 2013) 'degree of developing country ownership' (Smith, 2012) 
Table 3 Factors which influence outcomes (Continued)

\begin{tabular}{ll}
\hline Higher order themes & Lower order Components $\quad$ Examples from data \\
\hline & governments \\
& Countrywide initiatives \\
& Do volunteers have a project? \\
& How project is managed (i.e., \\
& Exill run) \\
& framence of guidelines and \\
& Commitment/time allocation/ \\
& number of UK admin staff \\
& Programme tailored to \\
& volunteer needs \\
& Spread of volunteers \\
& throughout the year \\
Quality control of services & provided by volunteers
\end{tabular}

Length of placement Long term

Short term

Adjustment

Short re-occurring trips

Project evaluations

Evaluations during placement Post-placement longitudinal evaluation

Project retention and

Volunteer drop out recruitment of volunteers How are volunteers recruited

Assessment and Education

Existence of set learning outcomes and objectives Use of assessment Use of model to facilitate contextual understanding

Time of programme arrangement

Training and preparation

In advance

In country

Appropriate training and preparation before placement Contact with previous volunteers

Debriefing

Encouraging people to share experience

Set training and preparation events

Health monitoring

Meeting in UK

Training and preparation in country

Volunteer involvement in planning

Type of organisation

Health Partnership Existing organisations Commercial involvement DIY/self-organised Remote or physical volunteering

Transferability of skills learnt Non-transferable skills Skills latency period Context dependency of skills

Volunteer dynamics within project the average time out being 12 months, you really have time to get to grips with trusting people when you are volunteering that it takes that long before you can kind of be comfortable with it.' (workshop participant)

The collection and application of feedback from hosts and volunteers, as well as the assessment of impact of such placements, are vital for ensuring that potential harms are mitigated and beneficial outcomes maximised (Elnaway, 2013)

'Retention of staff' (workshop participant)

'it's all about gaining global health knowledge, so that's their basic outcome, there's no assessment, its quite fluid' (workshop participant)

'Communications between Hereford and Muheza are difficult so details of each programme are arranged on arrival' (Wood, 1994)

'the intensity of the learning experience and pretrip preparation had a greater influence' (Button, 2005)

'subsequently question the actual benefit of their placement. Of note, this was despite the fact that all had received comprehensive pre-placement briefings and documents, and had had contact with previous volunteers' (Elnawaway, 2013)

'Links forged as trainees on these initial UROLINK visits have often been strengthened, and centres where these trainees have become consultants are now 'twinning' to continue the two-way exchange of experience.' (Gujral, 2002)

'Areas in which responders were most easily able to transfer competencies to the UK to a moderate or significant degree were personal qualities (such as selfawareness and integrity)' (Young, 2014)

Thus a broad range of departments become involved and a variety of activities are developed with the partner institution in the United Kingdom. As our experience grows, we are seeking to catalyse major links between medical schools and hospitals. This is preferable to a medley of individual links from a number of different institutions converging on a single overseas institution because it brings coherence to the goals of individuals and groups involved.' (Parry.. 1998)
Social support from other volunteers in country Planned travel to destination as a group 
Table 3 Factors which influence outcomes (Continued)

\begin{tabular}{|c|c|}
\hline Higher order themes & Lower order Components \\
\hline \multicolumn{2}{|l|}{ Volunteer Personal Variables } \\
\hline Choices made/behaviour & $\begin{array}{l}\text { Desire to become culturally } \\
\text { sensitive } \\
\text { Wanting to work outside of } \\
\text { competency } \\
\text { Willingness to work in } \\
\text { dangerous situations } \\
\text { Use of stress reduction } \\
\text { strategies } \\
\text { Understanding of local context } \\
\text { Communication with friends/ } \\
\text { home } \\
\text { Feeling like a foreigner } \\
\text { Being realistic about } \\
\text { achievements } \\
\text { Engagement with project } \\
\text { Willingness to learn language } \\
\text { Perception of placement as } \\
\text { negative or positive experience }\end{array}$ \\
\hline $\begin{array}{l}\text { Motivations for international } \\
\text { placement }\end{array}$ & $\begin{array}{l}\text { Professional/career motivations } \\
\text { Personal } \\
\text { Cultural } \\
\text { Recognition from peers } \\
\text { Desire to help other }\end{array}$ \\
\hline $\begin{array}{l}\text { Differences between } \\
\text { volunteers }\end{array}$ & $\begin{array}{l}\text { Level of advanced preparation } \\
\text { Age } \\
\text { Locum posts before or after } \\
\text { Have individuals volunteered } \\
\text { before? } \\
\text { Stage in professional career } \\
\text { Level of experience } \\
\text { Use of professional leave }\end{array}$ \\
\hline
\end{tabular}

'a LMI country may present a temptation to students to undertake medical care or procedures which they would not be permitted to perform at home' (Lumb, 2014) 'learning the local language will enable nurses to succeed in developing relationships with patients or nursing students. In doing so, they will begin to move to the third level of cultural competence' (Paterson, 2014)

'unclear whether those who participated wanted to learn from the experience or whether they saw themselves as aiding the perceived "unfortunate" (Button, 2005)

'the range of professionals that are not qualified so they have to be supervised when they go out' (workshop participant)

In practical terms, overseas working may be more accessible to younger GPs who have fewer family and financial commitments and may take up international work during training or during periods of job transition' (Smith, 2014)

$\begin{array}{ll}\text { Opportunities for reflection } & \text { Critical reflection } \\ & \text { Set reflection tasks } \\ & \text { Debrief } \\ & \text { Self-reflection when choosing a } \\ & \text { placement } \\ & \text { Time for post-placement } \\ & \text { reflection } \\ \text { Opportunities for clinical } & \text { To experience complex } \\ \text { exposure } & \text { situations and procedures } \\ & \text { To be thrown out of } \\ & \text { professional comfort zone } \\ & \text { To experience a different } \\ & \text { healthcare environment } \\ & \text { To experience a measure to } \\ & \text { compare UK and NHS to } \\ & \text { To experience unusual } \\ & \text { networks and hierachies } \\ & \text { To work with higher severity of } \\ & \text { illness } \\ & \text { To work with limited resources } \\ & \text { To work with many illnesses: } \\ & \text { spread and volume }\end{array}$

Opportunities for culturally Risk exposure different exposure

To engage with people from culturally diverse backgrounds To experience another culture To experience being a foreigner To experience challenging situations 'the process of critical reflection was uncomfortable for some. Critical reflection facilitated in a safe place may support individuals to transform their way of thinking' (Briscoe, 2013)

'Participation in health links provides in depth experience of these increasingly global pathologies' (Peate, 2008)

'cannot emphasise enough how seeing a mind-bogglingly large number of seriously ill people has helped ... in [their] subsequent career.' (Seo, 2012)

'being a foreigner- trigger for disturbance' (Greatex-White, 2008)

'the opportunity to work in complicated, poorly resourced and challenging environments' (Kiernan, 2014) 
Table 3 Factors which influence outcomes (Continued)

\begin{tabular}{|c|c|c|}
\hline Higher order themes & Lower order Components & Examples from data \\
\hline $\begin{array}{l}\text { Opportunities for skill } \\
\text { development }\end{array}$ & $\begin{array}{l}\text { To test coping mechanisms } \\
\text { To use own approaches to care } \\
\text { For creativity and innovation } \\
\text { For hands on work } \\
\text { For student/volunteer-centred } \\
\text { approach to learning } \\
\text { To use risk management skills } \\
\text { To convert knowledge to know } \\
\text { how } \\
\text { To develop communication } \\
\text { skills } \\
\text { To challenge communication } \\
\text { skills } \\
\text { To practice clinical skills } \\
\text { To practice speaking in another } \\
\text { language } \\
\text { To put theory into practice }\end{array}$ & $\begin{array}{l}\text { There was lots of hands-on experience and opportunities to improve clinical skills } \\
\text { (Kiernan, 2014) } \\
\text { 'opportunity to use skills- risk management' (Workshop participant) } \\
\text { 'the opportunity to develop their clinical skills.' (Barnabas, 1992) }\end{array}$ \\
\hline $\begin{array}{l}\text { Opportunities for research } \\
\text { skill development }\end{array}$ & $\begin{array}{l}\text { To research unusual areas } \\
\text { To undertake collaborative } \\
\text { research } \\
\text { To conduct research mutually }\end{array}$ & $\begin{array}{l}\text { 'Many doctors undertaking research in the UK become frustrated with its perceived } \\
\text { lack of relevance to health care: research in developing countries is often more } \\
\text { applied and the benefits more tangible' (Banatlava, 1997) }\end{array}$ \\
\hline Opportunities for leadership & $\begin{array}{l}\text { To be included and opinions } \\
\text { valued } \\
\text { For teaching } \\
\text { To lead and have responsibility } \\
\text { To use risk management skills }\end{array}$ & 'opportunities to develop leadership skills' Smith (2014) \\
\hline $\begin{array}{l}\text { Opportunities for atypical } \\
\text { learning experiences }\end{array}$ & $\begin{array}{l}\text { To learn about self } \\
\text { Mutual learning }\end{array}$ & $\begin{array}{l}\text { "Nursing electives at home or abroad may be one way of encouraging nurses } \\
\text { in the UK to consider their role and function from a different perspective" } \\
\text { (Peate, 2008) }\end{array}$ \\
\hline
\end{tabular}

After round 2, 98 of the 156 statements (63\%) were retained; this meant over $70 \%$ of the stakeholders agreed or strongly agreed these 98 statements were core outcomes. After re-considering their own vote in round 2 , the group median and anonymous comments regarding each statement, 13 additional statements were retained in round 3. Finally, after readdressing the above items for the second time, an additional five statements met consensus and were retained in round 4 . Of the items that met consensus, 99 were positive and eight were negative. Positive outcomes were of educational benefits to the British health professionals and negative outcomes were drawbacks, costs or negative effects (Tables 6, 7, 8, 9 and 10).

\section{Conclusion}

This study aimed to generate a list of core learning outcomes which might be developed through international placements and variables which might affect their development. We found 55 peer-reviewed papers and extracted 133 outcomes and 34 variables Table 3 . The most recent research to summarise learning outcomes

Table 4 Percentage of papers containing positive or negative outcomes

Positive outcomes $96 \%$

Negative outcomes 49\%

Variables $91 \%$
[3] found 40 individual benefits in seven domains: clinical skills, management skills, communication and teamwork, patient experience and dignity, policy, academic skills and personal satisfaction and interest. Our results support the domains but present the outcomes at a more granular level. For example, the previous review reports 'management skills' as a domain, which includes the outcome of 'leadership and management'. We extracted more granular knowledge, skills and attitudes which would map into the domain of 'management', such as ability to manage self, ability to lead by example and ability to manage risk. These more specific outcomes would lend themselves more to measurement due to the reported difficulties with assessment of domains $[15,16]$. By extracting outcomes at a granular level, we were also able to highlight many outcomes that do not fit neatly into any of the pre-defined categories of previous research such as 'ability to cope' or those that fit into more than one, i.e. 'ability to disseminate best practice globally'. Our study is the first to summarise the variables which have been assumed or proposed to influence learning in international placements, which will allow for hypothesis testing in the future. The outcome set provides a framework of personal and professional learning across healthcare professional groups. This is important as previous literature has tended to focus on specific professional 
Table 5 How the data extracted was coded, including higher-level outcomes, lower-level outcomes and examples from the data

Outcome: highest-order theme
Knowledge
Increased awareness of and
knowledge about how
communication between
two people can affect
understanding
Increased awareness of and
knowledge about conditions
and procedures rarely encountered
in the United Kingdom
Increased awareness of and
knowledge about the importance
of assessing healthcare on an individual
basis
Increased awareness of and knowledge
about the importance of community
participation in health

second-order theme

Effectively conveying ideas in an contextually appropriate way

Greater knowledge of procedures not used in the United Kingdom Better management of conditions that are not common in the United Kingdom

The uniqueness of each patient

The importance of community involvement in health

Awareness of the role of the community

in improving healthcare

Understanding the importance of community work

Increased understanding of basic skills and ideas

Increased awareness of and knowledge about clinical knowledge in relation to other professions

Increased awareness of and knowledge about the importance of mutual learning and respect

Understanding how to be a good teacher

Increased awareness of and knowledge about the importance of relationship maintenance skills

Increased awareness of and knowledge about the positive impact of clinical policies and governance

Increased awareness of and knowledge about tropical diseases

Increased awareness of and knowledge about appropriate clinical behaviour

Increased awareness of and knowledge about the cultural aspects of health
Core skills often replaced by technology (basic observations, using eyes, relying less on lab tests)

Doctors about nurses and vice versa

Understanding how to target training most effectively

Ability to suggest and acknowledge improvements in teaching Understanding importance of experiential learning

Consciously making an effort to get on with colleagues

Learning colleagues names

Greater policy skills

New knowledge of tropical diseases and increasing existing knowledge

Knowing when to ask for help Knowledge of different populations needs

Greater understanding and appreciation of health promotion Understanding how culture affects daily occupation Increased understanding of cultural differences in health Understanding the effects of politics on health Understanding how culture affects you professionally Understanding how to incorporate
Example data from source

'Effectively conveying and receiving ideas and messages in appropriate ways so that information is carried in context' (workshop participant)

'Experience of unfamiliar pathologies' [14]

"Experience has been gained in open operations now rarely performed in the UK, including vesico-vaginal fis tula surgery" (Gujral 2002)

"Enhanced the students' cultural awareness and made them more aware of the need to assess healthcare needs on an individual basis" [25]

"The investigators reported a significant growth in participants' awareness of how nurses interacted with the village as a community" [36]

'It kind of makes you go back and think about things in their fundamental... of course physics and that kind of thing' (workshop participant)

'Facilitate exploration of a different health care profession'. [36]

'Improved interdisciplinary teamwork' (Lee et al. 2011)

'Acknowledgement from the participants that the learning was a two way process' (Standage et al. 2014) 'Mutual respect' (workshop participant)

'Makes you drill down more and more what makes a good teaching programme' (workshop participant) 'Learning in this context has enabled me to suggest ways to improve the facilitation of learning'. (Lovatt et al. 2011)

Increased appreciation of and skills in maintaining of relationships' [3]

Work overseas will enable the health care worker to develop a greater understanding of socioeconomic and political determinants of health and consider the benefits of alternative health systems and health care initiatives'. (Banatlava, 1997)

'Knowledge of tropical diseases has increased' (Wood et al. 1994)

'Specifically for people from other cultures'. Remembering to let people speak to husband or want to pray. Not talking to baby when it comes out. '(workshop participant)

The noticeable lack of parental input in caring for their hospitalised children compared with UK culture and practice'. (Standage et al. 2014)

Increased understanding of the importance of culture in health care and the degree of variability in the countries they visited' [25] 
Table 5 How the data extracted was coded, including higher-level outcomes, lower-level outcomes and examples from the data (Continued)

\begin{tabular}{lll}
\hline Outcome: highest-order theme & Second-order theme & Example data from source \\
\hline & health beliefs into a shared decision \\
Greater understanding of sustainable &
\end{tabular}

Increased awareness of and knowledge about global issues

Increased awareness of and knowledge about cultural differences and similarities

Increased awareness of and knowledge about ethical considerations

Increased awareness of and knowledge about the need for/ importance of training

Increased awareness of and knowledge about how other healthcare systems function

Increased self-awareness

Increased awareness of and knowledge about finance in healthcare

Increased awareness of and knowledge about the resistance of culture

Increased awareness of and knowledge about culture in practical assessments

Increased awareness of and knowledge about the importance of trust within healthcare systems and staff

Increased awareness of and knowledge about how systems work
Re-evaluation of world issues

Deeper engagement with issues of equality and diversity Greater global knowledge

Understanding key issues within a culture

Understanding culturally acceptable behaviour

Learning about other cultures Being more attentive to subtle clues about cultural differences Accepting cultural differences Understanding of cultures of UK immigrants Changed assumptions of culture

Through experiential learning

Understanding how important effective training is in the United Kingdom and overseas

Developed insight into disparities within healthcare systems

Increased understanding and awareness of other systems

Awareness of own skills and limitations

Able to challenge own beliefs

Able to reflect on own situation Able to self-define

Awareness of the costs of healthcare

Understanding how to make small changes

Being innovative in overcoming language and cultural difference Understanding not to enforce your perspective onto others

Understanding importance of collecting relevant cultural information about people's presenting health problems Learning how to conduct cultural assessments and culturally based physical assessments

Understanding other people's perceptions of trust

Able to identify stakeholders and change agents Awareness of value systems Understanding influencing patterns of those in power Ability to assess impact of
"Both learners and institutions potentially will gain from an enhanced awareness of global health issues". (Lumb, 2014)

In Mexico it was inappropriate for them to discuss family planning methods with females because it was common for the males to exert control over such matters'.

(Standage et al. 2014)

They could apply this new understanding to immigrant communities in the UK who had come from these cultura backgrounds'. (Standage et al. 2014)

This process of challenging assumptions appeared to help student to appreciate the child rights stance promoted in the UK'. (Standage et al. 2014)

II recognised the need [for] teaching, so trained as a GP trainer'. (Smith et al. 2002)

'Gain a more effective measure by which to evaluate the strengths and weakness of their own country's health care system, and further develop insights into disparities' [36]

'Also made me more aware of my own values and beliefs and broadened my mind' (Greatex-White, 2008)

'There is an acute awareness of the costs of healthcare delivery especially when confronted by patients who have to pay for each intervention' (Longstaff, 2012)

'To demonstrate cultural competence, nurses should reflect on and recognise their own biases and be open to other perspectives, rather than trying to persuade others to see things their way'. (Paterson, 2014)

'Better understanding of cultural differences and of the need to acknowledge them in the delivery of health care'. (Paterson et al. 2014)

"Understanding of perceptions of trust, risk taking behaviour and approaches to risk management style". [6]

'Had come to understand a lot about how host countries health systems operate. They were also able to make direct comparisons with the British health care system' (Standage et al. 2014) 
Table 5 How the data extracted was coded, including higher-level outcomes, lower-level outcomes and examples from the data (Continued)

\begin{tabular}{lll}
\hline Outcome: highest-order theme & Second-order theme & Example data from source \\
\hline & healthcare systems Understanding \\
the difficulty of questioning an \\
organisation
\end{tabular}

Skills

Ability to overcome communication challenges

Ability to communicate non-verbally

Ability to provide better care

Ability to observe and examine patients

Ability to be innovative with clinical skills

Ability to use a broader range of clinical skills

Ability to apply clinical skills to another context

Ability to work with limited resources

Ability to 'get the best out of people'

Ability to manage risk

Ability to negotiate with multiple stakeholders

Ability to make independent clinical decisions

Ability to manage time and prioritise

Ability to work within a system with unfamiliar power systems

Ability to fulfil future leadership
Liase between groups

Engage senior people Negotiate with senior people

Developed non-verbal techniques

Ability to provide multicultural care

Ability to develop most

effective approaches to care

Taking responsibility for

providing quality care

Increased intuitive knowledge of clinical signs

Ability to make diagnosis without investigations Increased clinical judgement

Use of innovative techniques New ways of working)

Enhancing existing skills and acquiring new clinical skill

A more challenging environment or a low resource setting

Being more resourceful

Ability to target resource

Ability to find solutions despite limited resources

Ability to work without reliance on technology

Ability to manage in a low resource setting Understanding the reasons behind lack of resources

Encouraging people to work together Empowering people to recognise their own strengths and to take possession of their own work/projects

Ability to assess the capability of others Encouraging people to work together

Manage risk in advance Evaluation of environment Understanding the clinical importance of risk management Understanding the wider implication of poorly managed risk

Ability to make an urgent decision in an emergency

Dealing with uncertain outcomes

Ability to respond quickly in an emergency Prioritisation of limited resources
'Ability to have challenging conversations about sustainable change' (workshop participant)

'Developed nonverbal techniques' [36]

'Taking responsibility for developing quality of care' (Banatlava, 1997)

"In particular, UK doctors 'honed' their clinical diagnoses when laboratory confirmation was not available". [24]

'Innovation in healthcare delivery and use of resources' [3]

'Clinical skills were better and that the trainee had a broader range of skills' [35]

'They gained hands-on experience of care and developed a keen awareness of how the principles of nursing were applied in contexts very different from that to which they were used'. [25]

The nurses and doctors there are resourceful with what they have to use. I have learnt a lot and it has made me think differently. [4]

'Empowering them to recognise their strengths and not deskilling them' (workshop participant)

To manage risks they would not normally be exposed to' (Morgan, 2012)

'Improved skills of negotiation with multiple stakeholders' [3]

'More independent clinical decision making, eg in an emergency situation' (workshop participant)

'Time management and prioritisation' (workshop participant)

'Power relationships very difficult to manage' 'understanding the power context' (workshop participant)

'Prepare them for future leadership roles within their 
Table 5 How the data extracted was coded, including higher-level outcomes, lower-level outcomes and examples from the data (Continued)

\begin{tabular}{ll}
\hline Outcome: highest-order theme & Second-order theme \\
\hline $\begin{array}{l}\text { Ability to plan and organise } \\
\text { Ability to improve service }\end{array}$ & $\begin{array}{l}\text { Able to set direction } \\
\text { Including renewed enthusiasm } \\
\text { for service improvement }\end{array}$ \\
$\begin{array}{ll}\text { Ability to transfer skills and knowledge } \\
\text { to another context }\end{array}$ & $\begin{array}{l}\text { Solution focused approach } \\
\text { Ability to work towards solutions }\end{array}$ \\
$\begin{array}{l}\text { Ability to find facts to solve problems } \\
\text { Ability to make decisions }\end{array}$ & $\begin{array}{l}\text { Understanding who the decision is } \\
\text { for Taking action on decision } \\
\text { Make judgements }\end{array}$
\end{tabular}

Ability to co-operate

Ability to work as part of a team

Understanding team group norm Perception of roles within the group Managing personal objectives within a group

Ability to develop friendships

Ability to build a global network

Ability to give and accept praise

Ability to disseminate best practice globally

Ability to be professionally competent

Developed research skills

Ability to present work

Ability to write reports and academic pieces

Ability to apply knowledge gained in host system to the United Kingdom

Ability to cope

Ability to adapt social norms to meet needs of another culture

Ability to lead by example

Relationship formation skills Developing new friendships

Wider view of profession Intellectual development Reminder of professional responsibilities Stronger work ethic

Grant application skills Greater research skills

Greater presentation skills
Relating experiences back to the United Kingdom Using knowledge gained overseas to improve UK systems

Better coping strategies Ability to deal with knock backs

Being unfazed by things Learning to deal with stress

Change behaviour to fit with social norms

Example data from source profession' [36]

'Planning and organisation' (Pearson et al. 2014)

'Service improvement' [11]

'Applying those skills in a different context' (workshop participant)

'Solutions despite resource constraints' [36]

'They all recognised improvements in their ability to problem solve' (Longstaff, 2012)

'Better able to make decisions and take action' [36]

'Enhancing their own cooperation and communication skills' [24]

'At a professional level, the experience enhanced team-working skills' Longstaff, 2012)

'Fostering friendships' (Smith, 2012)

'They provide opportunities for personal and professional development of staff and promote the development of friendships and supportive networks between diverse communities"' (Bagguley et al. 2006)

'Appeared to be related to the giving and accepting of praise. In this context praise was meaningful and valued and often contrasted with the inanition of the home situation' (Greatex-White, 2008)

'Fosters international networking, which leads to the dissemination of best practices' (Horton, 2009)

'A wider view of their profession' (Horton, 2009)

'Experiential engagement with research is a desirable outcome' (Pearson et al. 2014)

'Ive seen them change considerable as people - by the end they are standing up and presenting their work and they really value that'. (workshop participant)

'I believe this not only enhances my effectiveness as an NHS consultant, hut also the lecturing, teaching and writing that I do reflects favourably on my hospital and university'. (Banatlava, 1997)

'Renewed enthusiasm for service improvement' (Conference)

I am more adaptable and can cope much easier with change' (Longstaff et al. 2012)

'Transcultural adaptation' [37]

'Leading by example with consistency and perseverance 
Table 5 How the data extracted was coded, including higher-level outcomes, lower-level outcomes and examples from the data (Continued)

\begin{tabular}{ll}
\hline Outcome: highest-order theme & Second-order them \\
\hline & \\
$\begin{array}{l}\text { Ability to exchange ideas with } \\
\text { those from another culture }\end{array}$ & $\begin{array}{l}\text { Communicate effective } \\
\text { from another country }\end{array}$ \\
$\begin{array}{l}\text { Ability to encourage others to } \\
\text { take responsibility for own health }\end{array}$ & \\
Ability to manage self & $\begin{array}{l}\text { Own expectations } \\
\text { Self-reliance } \\
\text { Self-management } \\
\end{array}$ \\
& Self-assurance
\end{tabular}

Example data from source

can be successful ways to improve practice' (Dowell et al. 2014)

Ability to manage projects

Analytical thinking Lateral thinking

Formal and informal

Greater training delivery skills

Ability to apply theory

Ability to use evidence based practice

Ability to speak host language

Attitudes

Confidence to work in other locations

Independence

Integrity

Diplomacy

Humility

Judgement

Proactivity

Increased cultural sensitivity

Increased respect for other cultures

Reinforced ethnic and cultural identity

Patience and tolerance

Increased confidence
Confidence to move to another city/country

Working with UK multicultural/ underserved populations

Non-judgemental attitude Changed self-judgement

Using initiative

Sensitivity to reasoning behind cultural differences

Sensitivity towards feelings of minority Sensitivity towards

language barriers

Positivity about being British

Accepting and working at other peoples pace More tolerance

In caring for clients from another culture

In quality improvement methods

To take bolder steps

Self-confidence gained significant experience in report writing, project planning, managing budgets and particularly human resources'. [11]

'The experience of clinical practice in a low resource environment stimulated lateral thinking' (Lee et al. 2011)

'Establishing communication systems, both formal and informal'. [6]

'But nurses/midwives - confidence and skills really increase, do not do teaching in the UK' (workshop participant)

Use evidence-based practice effectively and develop a broader and more sophisticated understanding of occupation' (Dowell et al. 2009)

'Some people would learn new language, this could depend on how rural you are'. (workshop participant)

'To live and work independently in a new community and culture'. (Morgan,2012)

'Autonomy/independence' [36]

'Integrity' [11]

'Utilising diplomacy skills' (workshop participant)

'Knowing that you are sometimes wrong' (Conference notes)

'Yes and taking things less as face value and less judgemental'. (Workshop participant)

'Initiative' (Pearson et al. 2014)

'It involves an awareness and acceptance of cultural differences' (Paterson, 2014)

'An understanding of and respect for other cultures' (Horton, 2009)

"Having become a foreigner in the host country, there remained a sense of being tied to the home culture" (Greatex-White, 2008)

'Made them more tolerant of others' [25]

'Confidence about caring for clients whose culture differed from their own' (Briscoe, 2013) 
Table 5 How the data extracted was coded, including higher-level outcomes, lower-level outcomes and examples from the data (Continued)

\begin{tabular}{lll}
\hline Outcome: highest-order theme & Second-order theme & Example data from source \\
\hline & Confidence in professional ability \\
& In ability to address challenging \\
situations
\end{tabular}

Flexibility and adaptability

Emotional intelligence

Appreciation of importance of care and compassion

Changed perception of otherness

Appreciation of excellent human resource in the NHS

Appreciation of having the right tools and equipment to be able to do the job

Appreciation of free universal health

Appreciation of clinical governance procedures within NHS

\section{Organisational outcomes}

Increased staff knowledge and skills

Increased international reputation of NHS

NHS becomes a more attractive employee (If offers staff opportunity to volunteer)

Increased patient satisfaction
Acceptance of other ways of working Adaptation to responsibility

Able to adapt more easily to unfamiliar situations

Able to cope more easily with change

Able to manage change

Gaining a wider perspective

Understanding the flexibility of roles

Changed engagement with self

Knowledge and world

Empathy

Understanding importance of being a friendly stranger in the United Kingdom

Experienced feeling like a foreigner whilst away

Multidisciplinary teams

HR structures

Appreciation of own profession Understanding hierarchy and the importance of each person within it Interaction between healthcare professionals

Resources: technical equipment, disposal equipment, cleaning products and protective equipment

NHS system of free healthcare for all Privilege and opportunity for UK citizens

Understanding the expectations that are placed on NHS by service users

Waste disposal

Audit

Teamwork

Education system

Tests and investigations

Understanding that systems are not restricting

Increased staff knowledge of lowcost healthcare

More knowledgeable staff

Staff able to discover better ways of doing things

Staff more aware of waste reduction

Greater fulfilment of social responsibility)

Staff better able to respond to UK multicultural populations Staff have greater relationships with multicultural patient population
'Flexibility/humility: Accepting different ways of working' (workshop participant)

'Emotional intelligence' (workshop participant)

'Greater empathy and understanding' [37]

'Learning cultural differences gave students the rare chance of being in a minority status, with the consequential experience of living and surviving in a foreign culture - an experience that students reported as 'more valuable than a mere excursion' (Morgan, 2012)

'Through lack of team working they appreciated Resources - material and human' (workshop participant)

'Greater appreciation of the resources' (Lee et al. 2014)

'Able to comment and reflect on issues around the perceived inequalities of insurance based healthcare systems' (Standage et al. 2014)

'And a greater understanding of why we need to do the things that we do, like gaining consent from a child' (Standage et al. 2014)

'Makes people more adaptable when they come back because in some areas if you have not move ward for twenty years, it is trauma just to be asked and work in ward $X$ in the same hospital is not it? If you have got somebody that has been exposed to a range of environment, they are more likely to cover shifts'. (workshop participant)

'Reputational development' [3]

'Link attracts potential staff' [24]

'Patient experience and dignity: understanding of patients from different areas' [3] 
Table 5 How the data extracted was coded, including higher-level outcomes, lower-level outcomes and examples from the data (Continued)

\begin{tabular}{|c|c|}
\hline Outcome: highest-order theme & Second-order theme \\
\hline & $\begin{array}{l}\text { Staff more in tune with patients } \\
\text { Staff more aware of individual } \\
\text { needs of patients }\end{array}$ \\
\hline \multicolumn{2}{|l|}{$\begin{array}{l}\text { Medical school more attractive } \\
\text { to students (if allow students to } \\
\text { go abroad) }\end{array}$} \\
\hline \multicolumn{2}{|l|}{ Increased workforce productivity } \\
\hline Reduction in NHS drop outs & Increased staff retention \\
\hline \multicolumn{2}{|l|}{$\begin{array}{l}\text { Increased international reputation } \\
\text { (of the United Kingdom) }\end{array}$} \\
\hline \multicolumn{2}{|l|}{ Miscellaneous outcomes } \\
\hline \multicolumn{2}{|l|}{$\begin{array}{l}\text { Upper hand when competing } \\
\text { for careers }\end{array}$} \\
\hline Increased job satisfaction & $\begin{array}{l}\text { Increased motivation and morale } \\
\text { with profession } \\
\text { Renewed passion for work } \\
\text { Sense of reward }\end{array}$ \\
\hline Influence career pathway & $\begin{array}{l}\text { Affects specialism choice } \\
\text { Exploration of potential } \\
\text { career pathways } \\
\text { Pursuing careers in primary care, } \\
\text { family practice, and public service } \\
\text { Sub-specialism in global health, } \\
\text { Teaching or lecturing careers } \\
\text { Teaching responsibilities within } \\
\text { clinical position }\end{array}$ \\
\hline
\end{tabular}

Refreshment and reinvigoration

Personal satisfaction

Increased motivation to learn a language

Development of a new perspective

Escapism

Negative outcomes

Costs to British patients
Coming back to the United Kingdom refreshed and reinvigorated Bringing new ideas to the United Kingdom

Personal achievements and challenges New experiences

Experiencing a different lifestyle

A holiday

Personal fulfilment

Revising assumptions Reassessed outlook on life Seeing things differently Changed world views

Changed outlook Look at everything in a new light Openness to new experiences Put things into perspective

Escape from agendas and workload A chance to take time out of training and practice

Space to think and clarify career objectives

Bringing tropical illness to the United Kingdom
'Medical school benefits (programme are increasingly attractive, potentially providing a strong tool for recruitment)' (Miranda et al. 2005)

'Increased workforce productivity' [3]

'Attraction \& retention of (more/better quality) workforce' [3]

'96 per cent of health professionals interviewed for the study thought that the reputation of the NHS could only be enhanced by involvement in international health links'. (Longstaff, 2012)

'Working internationally is beneficial when competing for future employment' (Paterson, 2014)

'They came back with greater job satisfaction' (Longstaff, 2012)

'Such broadening experiences are recognized to impact upon the likelihood of working with underserved populations, and pursuing careers in primary care or public service' (Lumb, 2013)

With a rekindling of that initial desire to "change the world and help people" and refresh those values underpinning their initial vocational drive to enter the profession'. (Lumb, 2013)

'An opportunity to travel, experience and work in a different setting, and to make a positive impact' (Elanaway et al. 2014)

'Enhanced your motivation and/or ability to learn a foreign language after returning to Northern Ireland?' (Thompson 2000)

They were beginning to see differently and to compare aspects of the host environment with those of home, leading to new perspectives on life' (Greatex-White, 2008)

'They want to escape the hassle of home'. (workshop participant)

'It is not uncommon for a few students each year to return from their elective unwell, with some of the infectious diseases occasionally brought back from electives not becoming apparent for some time, e.g. tuberculosis or malaria. This has significant public 
Table 5 How the data extracted was coded, including higher-level outcomes, lower-level outcomes and examples from the data (Continued)

\begin{tabular}{|c|c|}
\hline Outcome: highest-order theme & Second-order theme \\
\hline $\begin{array}{l}\text { Developing redundant or bad } \\
\text { skills/attitudes }\end{array}$ & $\begin{array}{l}\text { Non-transferable skills } \\
\text { Bad habits } \\
\text { Deskilling } \\
\text { Overconfidence in ability } \\
\text { Poorer communication skills } \\
\text { Loss of confidence }\end{array}$ \\
\hline $\begin{array}{l}\text { Difficulty getting the job you want } \\
\text { on return }\end{array}$ & Permanent jobs or training contracts \\
\hline Loss of trained staff & $\begin{array}{l}\text { Utilisation of key staff time } \\
\text { Financial cost of losing staff } \\
\text { Having to find cover for staff }\end{array}$ \\
\hline Negative perceptions of NHS & $\begin{array}{l}\text { Reputational } \\
\text { When program run badly }\end{array}$ \\
\hline \multicolumn{2}{|l|}{ Distracted staff } \\
\hline Exposure to ethical dilemmas & $\begin{array}{l}\text { To work outside of competency } \\
\text { Lack of regulation } \\
\text { Too much responsibility }\end{array}$ \\
\hline \multicolumn{2}{|l|}{$\begin{array}{l}\text { No recognition of accreditation } \\
\text { upon return }\end{array}$} \\
\hline $\begin{array}{l}\text { Reduced experience and exposure } \\
\text { to UK procedures, protocols and } \\
\text { research }\end{array}$ & $\begin{array}{l}\text { No experience with NHS procedures that } \\
\text { do not exist in host country } \\
\text { Missing out on formal training and } \\
\text { conferences } \\
\text { No experience with chronic disease } \\
\text { management over time } \\
\text { No experience with health conditions that } \\
\text { are common in the United Kingdom and } \\
\text { not in host country } \\
\text { Unaware of NHS protocol and updates } \\
\text { Loss of professional networks and } \\
\text { relationships }\end{array}$ \\
\hline
\end{tabular}

Affects professional progression

Negative colleague perceptions

Use of time

Professional revalidation issues

Litigation

Security

Carbon footprint

Culture shock

Environmental and infrastructural risk
Example data from source

health implications' (Lumb, 2013)

"They may be left to 'do their best' to manage heavy workloads with limited or no supervision, leading to the acquisition of poor practice habits". (Barnabas, 2012)

"Many of them experienced discouragement and warnings of 'career suicide' when proposing to opt out from accepted career pathways in Britain to work in the developing world for a short period'. (Connelly, 1995)

'Trained staff leaving their post following links' [3]

'Negative perception of the UK institution where links are run badly' [3]

'Distracts staff from their work at the institution' [3]

'To encounter challenging ethical scenarios, particularly those students venturing to developing countries' (Banatlava, 1998)

'Training and accreditation issues' (Banatlava, 1998) 'Lack of accreditation/recognition' (workshop participant)

'Referral experience more limited' [35]

'Things might be outdated' (workshop participant)

"The threat of having to 'retrain' is ludicrous when I am working in a developed country in a primary care setting essentially modeled on the British system". [2]

'Negative perception of gaps in training programmes' (workshop participant)

'Staff generally use their

'annual leave for the trips'. [4]

For consultants

'Another common barrier was keeping up appraisal in light of the recent changes to GP revalidation'. [11]

Legal issues involving clinical/professional risk

'Clinical-professional risk- litigation' (Morgan, 2012)

Exposure to aggression

Violence and death

Becoming a victim of crime

Political unrest

'Examples range from involvement in criminal activity (either as perpetrator or victim)' (Lumb, 2014)

'Another health and safety issue is the carbon footprint'. (Pearson et al. 2014)

'Culture shock due to the contextual differences and challenges faced in resource poor settings'. [3]

'Physical risk to person- environment, infrastructure' 
Table 5 How the data extracted was coded, including higher-level outcomes, lower-level outcomes and examples from the data (Continued)

\begin{tabular}{|c|c|c|}
\hline Outcome: highest-order theme & Second-order theme & Example data from source \\
\hline & & (Morgan, 2012) \\
\hline $\begin{array}{l}\text { Extreme nationalism towards the } \\
\text { United Kingdom }\end{array}$ & & $\begin{array}{l}\text { 'Developing negative attitudes towards host } \\
\text { culture- causes retreat back to culture of origin and } \\
\text { even extreme nationalism' (Greatex-White, 2008) }\end{array}$ \\
\hline Experiencing negative feelings & $\begin{array}{l}\text { Feeling as though imposing on UK } \\
\text { colleagues to provide cover } \\
\text { Feeling out of depth } \\
\text { Frustration } \\
\text { Guilt and regret about death }\end{array}$ & $\begin{array}{l}\text { II was subjected to the feelings of guilt and regret } \\
\text { which accompany the death of a patient under one's } \\
\text { care' (Robinson, 2014) }\end{array}$ \\
\hline Financial loss & $\begin{array}{l}\text { Costs of getting involved } \\
\text { Loss of earnings } \\
\text { Loss of pension or employment } \\
\text { entitlement }\end{array}$ & 'Costs of getting involved' [4] \\
\hline Health consequences & $\begin{array}{l}\text { Animal bites } \\
\text { Tropical diseases } \\
\text { Sexually Transmitted Disease } \\
\text { Injuries and transport accidents } \\
\text { Infection } \\
\text { Jet lag } \\
\text { Skin disease }\end{array}$ & $\begin{array}{l}\text { ' } 11.1 \% \text { were concerned that they } \\
\text { had placed themselves at risk of HIV and STIs. } \\
\text { Unprotected sexual intercourse was the most } \\
\text { commonly reported reason'. [20] }\end{array}$ \\
\hline Psychological consequences & $\begin{array}{l}\text { Depression } \\
\text { Anxiety } \\
\text { Stress } \\
\text { Nervousness }\end{array}$ & $\begin{array}{l}\text { 'Psychological problems on return from their } \\
\text { placements' [20] }\end{array}$ \\
\hline Exhaustion and burn out & & 'Exhaustion/Burnout/Stress' [3] \\
\hline Loneliness & $\begin{array}{l}\text { Isolation } \\
\text { Social isolation } \\
\text { No or few friends in host country }\end{array}$ & $\begin{array}{l}\text { 'You will often be doing lone working which will be } \\
\text { very high risk and that happens an awful lot'. } \\
\text { (workshop participant) }\end{array}$ \\
\hline Missing things at home & $\begin{array}{l}\text { Missing life in the United Kingdom } \\
\text { Time away from family and friends }\end{array}$ & 'Time away from their family' [36] \\
\hline $\begin{array}{l}\text { Loss of interest in global health } \\
\text { and international placements }\end{array}$ & $\begin{array}{l}\text { Negative perceptions of volunteering and } \\
\text { international placements }\end{array}$ & $\begin{array}{l}\text { 'Many reported negative experiences and never } \\
\text { wanted to do it again' (Conference speaker) }\end{array}$ \\
\hline Socio-cultural risk & $\begin{array}{l}\text { Exposure to corruption } \\
\text { Experiencing resistance to western } \\
\text { influence }\end{array}$ & $\begin{array}{l}\text { 'Socio-cultural risk- dress like them, did not want } \\
\text { English influence, corruption' (Morgan, 2012) }\end{array}$ \\
\hline Become judgemental & & $\begin{array}{l}\text { 'Go home with a judgmental opinion of some of the } \\
\text { people I look after'. (workshop participant) }\end{array}$ \\
\hline
\end{tabular}

cadres, so this COS would allow comparison and collation across professional groups [35, 36].

Our study generated a list of 28 potential negative outcomes. It is interesting that only eight of these were retained in the Delphi, i.e. stakeholders were in

Table 6 Number of statements retained at each stage with 70\% consensus being met

\begin{tabular}{llll}
\hline Round & $\begin{array}{l}\text { Number of Statements } \\
\text { retained }(n=156)\end{array}$ & $\begin{array}{l}\text { Positive } \\
\text { outcomes }\end{array}$ & $\begin{array}{l}\text { Negative } \\
\text { outcomes }\end{array}$ \\
\hline 2 & 98 & 97 & 1 \\
3 & 13 & 10 & 3 \\
4 & 5 & 1 & 4 \\
$\begin{array}{l}\text { Did not meet } \\
\text { consensus }\end{array}$ & 40 & 14 & 26 \\
\hline
\end{tabular}

agreement that these negative outcomes were either not likely to happen or likely to happen to a range of healthcare professionals. Only one negative outcome was considered core: 'health consequences'. This indicates that stakeholders believe almost all negative outcomes do not happen on many or most placements. There is much less consensus about the negative aspects of placements.

The literature contains stated or implied variables which might influence learning on international placements, and this study has synthesised these, finding 33 variables. This provides a framework for future research that aims to study the interactions between variables and outcomes by empirically testing some of the hypotheses reported or assumed in the literature.

Historically, international volunteering has been conceptualised as a benefit to the LMIC and a loss to the HIC $[8,9]$. Recent policy documents explicitly discuss 


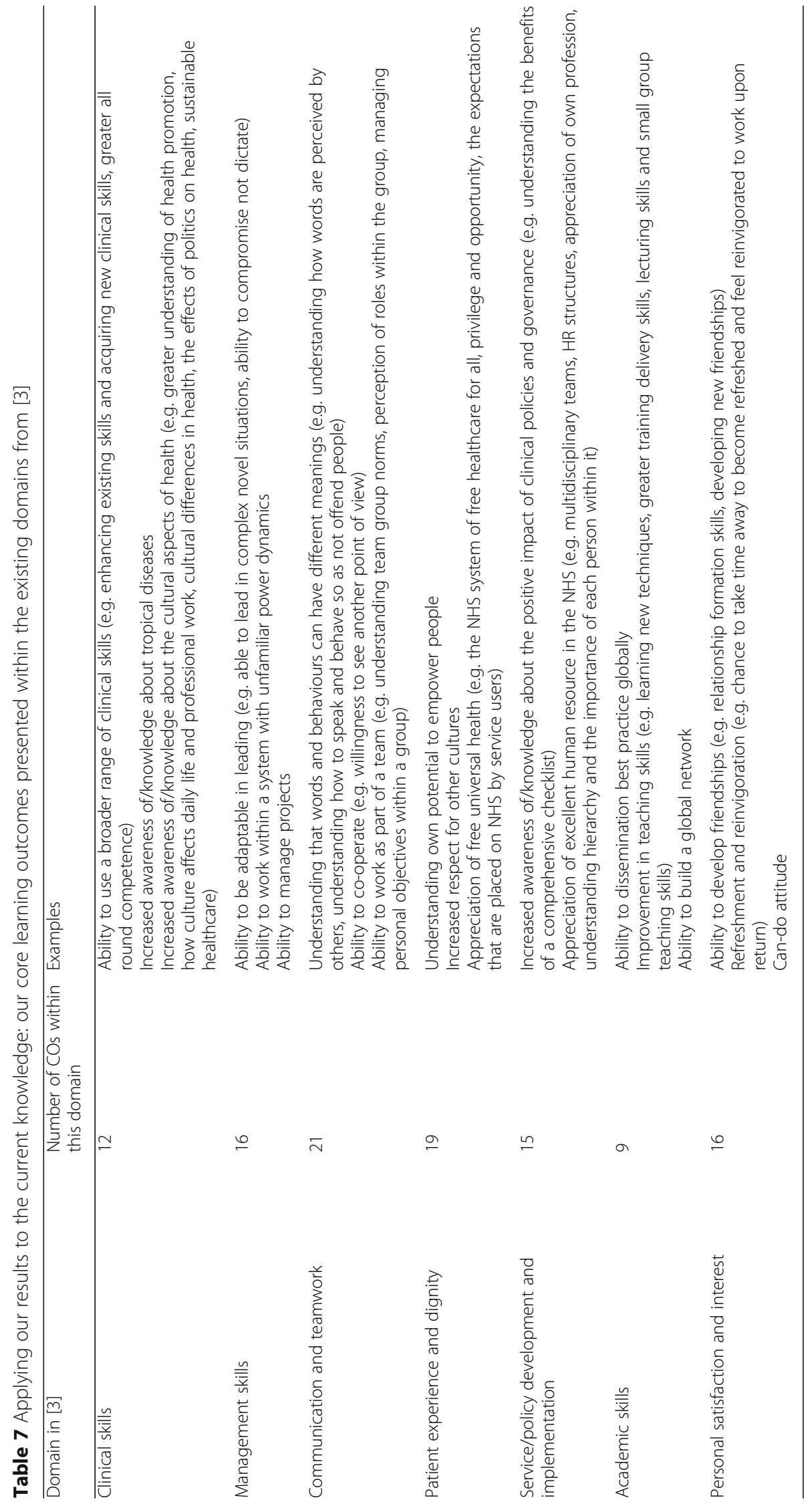


Table 8 Examples of COs that fell within a number of categories

\begin{tabular}{ll}
\hline Example & Categories \\
\hline Increased awareness/knowledge about clinical conditions and & Clinical, academic \\
procedures rarely encountered in the United Kingdom & Patient experience and dignity, communication and \\
$\begin{array}{l}\text { Increased awareness of/knowledge about the importance of } \\
\text { mutual learning and respect }\end{array}$ & team work \\
Ability to disseminate best practice globally & $\begin{array}{l}\text { Communication and team work, academic, service } \\
\text { improvement and policy }\end{array}$ \\
Ability to develop friendships & Personal, communication and team work \\
\hline
\end{tabular}

the benefit to UK health professionals in terms of personal and professional development and the necessity to develop competencies to be used in training curricula [9]. This study will facilitate the specification and exploration of learning outcomes and so in the future help in addressing the imbalanced discourse of the "benefitting LMIC" and the "donor HIC". Additionally, a recent Royal College policy describes what competencies paediatricians need to work globally, or with a global population in the United Kingdom [37]. Many of the competencies described map onto the core outcome set suggesting that international placements themselves may provide a vehicle for developing these necessary competencies. In fact, the core outcome set maps onto policy documents such as the Health Education England (HEE) Framework 15: 2014-2029, which suggests the future NHS workforce needs to be flexible, open to innovation and change and life-long learners (all components of the COS) [18]. The core outcome set provides a way of framing and evidencing the NHS benefits. Future work will focus on how the core outcome set can be used as a tool to measure outcomes. The research has also influenced the production of the Health Education England Global strategy, which aims to embed global learning opportunities into NHS training [38].

In summary, there is a broad range of learning outcomes which we have synthesised into a set of 116 core outcomes agreed by a group of 45 stakeholders from various invested groups that could be used in future assessment of learning and testing of hypotheses about what leads to or detracts from learning. We also extracted 33 variables from the literature. We reported a list of negative outcomes, as well as every variable that has been reported (implicitly or explicitly) to affect

Table 9 Examples of core learning outcomes that did not fit within the categories

Core outcome
Improved flexibility and adaptability
Ability to be innovative when overcoming challenges
Ability to cope
Improved situational awareness

learning. The core outcome set and variables will enable the development of assessments of health professional learning in international placements, which has implications for how international placements are created and on the support for international placements amongst UK healthcare organisations.

\section{Limitations}

This study has a number of limitations. Firstly, we did not update the systematic review because this was the first stage of the outcome set development, and therefore, new outcomes could not be added. We conducted a scoping search using the same search strategy in March 2018 and found 23 new papers had been published. We read these papers and did not find any new outcomes or variables reported. Secondly, the papers included in the meta-synthesis included both those with primary data and those which did not. Formal risk of bias assessment, using standard tools, was therefore not possible. However, it is important to note that the papers included and the findings of the Delphi indicate an overall positive attitude towards international placements, with $96 \%$ of papers in the review reporting positive outcomes as opposed to $49 \%$ reporting negative outcomes. It is possible that there is publication bias, in which reports of negative experiences are less likely to be written and/or accepted for publication. In the Delphi, participants agreed most of the positive outcomes were core and very few negative. It may be that Delphi participants (particularly those who choose to dedicate hours of their own time) feel more positively about the outcomes than those that were invited but chose not to participate. This represents a risk of bias both in terms of an underreporting of negative outcomes and an inconsistent reporting of variables, with variables influencing outcomes being reported by people whose outcomes had been positive.

\section{Future research and recommendations}

The core outcome set could be developed into a tool to assess outcomes. Measurement of learning outcomes is not straightforward, and self-report of learning is fraught with difficulties, including people not knowing what they 
Table 10 List of all outcomes and those that met consensus (those that met consensus were included in the core outcome set)

\begin{tabular}{|c|c|c|c|c|}
\hline Core outcome & $\begin{array}{l}\text { Met consensus } \\
\text { at round }\end{array}$ & $\begin{array}{l}\text { Percentage } \\
\text { consensus }\end{array}$ & $\begin{array}{l}\text { Include or } \\
\text { exclude }\end{array}$ & Rank \\
\hline $\begin{array}{l}\text { Increased awareness of/knowledge about cultural differences and similarities (e.g. understanding key } \\
\text { issues within a culture, culturally acceptable behaviour and cultures of UK immigrants, learning about, } \\
\text { accepting and changing assumptions about other cultures) }\end{array}$ & 2 & 100 & + & 1 \\
\hline $\begin{array}{l}\text { Increased awareness of/knowledge about the cultural aspects of health (e.g. greater understanding } \\
\text { of health promotion, how culture affects daily life and professional work, cultural differences in } \\
\text { health, the effects of politics on health, sustainable healthcare) }\end{array}$ & 2 & 100 & + & 1 \\
\hline $\begin{array}{l}\text { Ability to work with limited resources (e.g. being more resourceful, ability to target resources, } \\
\text { ability to find solutions despite limited resources, making use of everything available, ability to } \\
\text { work without reliance on technology, manage in a low resource setting) }\end{array}$ & 2 & 95 & + & 3 \\
\hline $\begin{array}{l}\text { Increased awareness of/knowledge about culture in practical assessments (e.g. the importance } \\
\text { of collecting relevant cultural information about people's presenting health problems and learning } \\
\text { how to conduct cultural assessments and culturally based physical assessments) }\end{array}$ & 2 & 93 & + & 4 \\
\hline $\begin{array}{l}\text { Ability to apply clinical skills to another context (e.g. a more challenging environment or a low } \\
\text { resource setting) }\end{array}$ & 2 & 93 & + & 4 \\
\hline $\begin{array}{l}\text { Ability to be adaptable and innovative in teaching (e.g. ability to transfer skills and knowledge to } \\
\text { the most influential people or to another context, recognising different learning styles, being } \\
\text { adaptable in assessment) }\end{array}$ & 2 & 93 & + & 4 \\
\hline $\begin{array}{l}\text { Increased awareness of/knowledge about how other healthcare systems function (e.g. developed } \\
\text { insight into disparities within healthcare systems, understanding of other systems) }\end{array}$ & 2 & 93 & + & 4 \\
\hline $\begin{array}{l}\text { Ability to cope (e.g. improved coping strategies, ability to deal with lack of structure, knock backs } \\
\text { and stress, being unfazed by things and taking things in stride, new approach to guilt for patients } \\
\text { problems) }\end{array}$ & 2 & 93 & + & 4 \\
\hline $\begin{array}{l}\text { Increased cultural sensitivity (e.g. sensitivity to reasoning behind cultural differences, feelings of } \\
\text { minority and language barriers) }\end{array}$ & 2 & 91 & + & 9 \\
\hline $\begin{array}{l}\text { Understanding that words and behaviours can have different meanings (e.g. understanding } \\
\text { how words are perceived by others, understanding how to speak and behave so as not offend } \\
\text { people) }\end{array}$ & 2 & 91 & + & 9 \\
\hline $\begin{array}{l}\text { Ability to apply knowledge across systems (e.g. ability to apply knowledge from host system } \\
\text { to United Kingdom and vice versa, using knowledge gained in system to improve/change } \\
\text { another) }\end{array}$ & 2 & 91 & + & 9 \\
\hline $\begin{array}{l}\text { Development of a new perspective (e.g. revising assumptions, seeing things differently, } \\
\text { changed world views and outlook, look at everything in a new light, openness to new } \\
\text { experiences, put things into perspective) }\end{array}$ & 2 & 91 & + & 9 \\
\hline $\begin{array}{l}\text { Improved flexibility and adaptability (e.g. acceptance of other ways of working, adaptation to } \\
\text { responsibility, being able to adapt more easily to unfamiliar situations, able to cope more easily } \\
\text { with change, gaining a wider perspective, understanding the flexibility of roles) }\end{array}$ & 2 & 91 & + & 9 \\
\hline $\begin{array}{l}\text { Ability to be innovate when overcoming challenges (i.e. finding unique ways of overcoming } \\
\text { cultural and language challenges) }\end{array}$ & 2 & 91 & + & 9 \\
\hline Increased respect for other cultures & 2 & 90 & + & 15 \\
\hline $\begin{array}{l}\text { Increased understanding of basic skills and ideas (i.e. back to basics, e.g. basic observations } \\
\text { using eyes, less reliance on lab tests and technology, basic clinical skills and science) }\end{array}$ & 2 & 90 & + & 15 \\
\hline $\begin{array}{l}\text { Confidence in teaching ability (e.g. being more comfortable around others, confidence public } \\
\text { speaking, confidence in transferring knowledge) }\end{array}$ & 2 & 90 & + & 15 \\
\hline $\begin{array}{l}\text { Improved confidence (e.g. in caring for clients from another culture, in quality improvement } \\
\text { methods, to take bolder steps, to address challenging situations, self-confidence, confidence } \\
\text { in professional ability, }\end{array}$ & 2 & 90 & + & 15 \\
\hline $\begin{array}{l}\text { Confidence to work in other locations (e.g. confidence to move to another city/country, working } \\
\text { with UK multicultural/underserved populations) }\end{array}$ & 2 & 89 & + & 19 \\
\hline $\begin{array}{l}\text { Increased awareness of/knowledge about global issues (e.g. re-evaluating world issues, } \\
\text { shared purpose) }\end{array}$ & 2 & 88 & + & 20 \\
\hline $\begin{array}{l}\text { Increased awareness of/knowledge about conditions and procedures rarely encountered in } \\
\text { the United Kingdom (e.g. greater understanding of procedures not used in the United Kingdom, } \\
\text { unfamiliar equipment and delayed presentations, better management of conditions that are not } \\
\text { common in the United Kingdom) }\end{array}$ & 2 & 88 & + & 20 \\
\hline & 2 & 88 & + & 20 \\
\hline
\end{tabular}


Table 10 List of all outcomes and those that met consensus (those that met consensus were included in the core outcome set) (Continued)

Core outcome

Met consensus Percentage Include or Rank at round consensus exclude

Increased awareness of/knowledge about the importance of mutual learning and respect (i.e. greater understanding of reciprocal learning)

Ability to be adaptable in leading (e.g. able to lead in complex novel situations, ability to compromise not dictate)

Ability to work within a system with unfamiliar power dynamics

Ability to adapt social norms to meet needs of another culture (e.g. change behaviours to fit into another culture, being aware of own social norms and adapting them)

Ability to exchange ideas with those from another culture

Increased self-awareness (e.g. understanding own skills and limitations, how to challenge own beliefs and importance of reflecting on own situation)

Patience and tolerance (e.g. accepting and working at other peoples pace, more tolerant)

Proactivity (e.g. thinking on feet, using initiative, efficiency, get on with things rather than look for someone to blame)

Ability to work with resources available in specific contexts (i.e. understanding the reasons behind lack of resources)

Ability to work towards solutions (e.g. solution focused approach)

Understanding that speed and language competency affect communication (e.g. awareness of how speed affects comprehension, understanding language differences and checking recipient comprehension, ability to use an interpreter)

Increased awareness of/knowledge about the importance of community participation in health (e.g. understanding the community and social influences on health, the role of the community in health, public health and the importance of community work)

Ability to use a broader range of clinical skills (e.g. enhancing existing skills and acquiring new clinical skills, greater all round competence)

Understanding that changing behaviour is complex (e.g. understanding how to make small changes and not to force your perspective onto others,)

Ability to improve service (e.g. renewed enthusiasm for service improvement)

Increased staff knowledge and skills (e.g. increased staff knowledge of low cost healthcare, more knowledgeable staff able to cover more areas, to discover better ways of doing things and more aware of waste reduction)

Increased awareness of/knowledge about how context affects communication (e.g. effectively conveying ideas in a contextually appropriate way)

Increased awareness of/knowledge about the need for and importance of training (i.e. understanding how important effective training is in)

Improvement in teaching skills (e.g. learning new techniques, greater training delivery skills, lecturing skills and small group teaching skills)

Ability to deal with the unexpected

Ability to manage projects

Deeper engagement with issues of equality and diversity

Ability to overcome communication challenges (e.g. ability to communicate effectively in high pressure situations, engage in challenging conversations and liaise between groups)

Ability to be innovative with clinical skills (e.g. use of innovative techniques, finding new ways to approach a condition, new ways of working)

Appreciation of having the right tools and equipment to be able to do the job (i.e. resources: technical equipment, disposal equipment, cleaning products and protective equipment)

Appreciation of excellent human resource in the NHS (e.g. multidisciplinary teams, HR structures, appreciation of own profession, understanding hierarchy and the importance of each person within it)

Improved emotional intelligence (e.g. changed engagement with self, knowledge and world)

Ability to identify and anticipate potential problems (e.g. identify problems when setting up a

\begin{tabular}{|c|c|c|c|}
\hline 2 & 88 & + & 20 \\
\hline 2 & 88 & + & 20 \\
\hline 2 & 88 & + & 20 \\
\hline 2 & 88 & + & 20 \\
\hline 2 & 88 & + & 20 \\
\hline 2 & 88 & + & 20 \\
\hline 2 & 88 & + & 20 \\
\hline 2 & 88 & + & 20 \\
\hline 2 & 88 & + & 20 \\
\hline 2 & 88 & + & 20 \\
\hline 2 & 86 & + & 33 \\
\hline 2 & 86 & + & 33 \\
\hline 2 & 86 & + & 33 \\
\hline 2 & 86 & + & 33 \\
\hline 2 & 86 & + & 33 \\
\hline 2 & 86 & + & 33 \\
\hline 2 & 84 & + & 39 \\
\hline 2 & 84 & + & 39 \\
\hline 2 & 84 & + & 39 \\
\hline 2 & 84 & + & 39 \\
\hline 3 & 84 & + & 99 \\
\hline 2 & 83 & + & 43 \\
\hline 2 & 83 & + & 43 \\
\hline 2 & 83 & + & 43 \\
\hline 2 & 83 & + & 43 \\
\hline 2 & 83 & + & 43 \\
\hline 2 & 83 & + & 43 \\
\hline 2 & 83 & + & 43 \\
\hline
\end{tabular}


Table 10 List of all outcomes and those that met consensus (those that met consensus were included in the core outcome set) (Continued)

Core outcome

Met consensus Percentage Include or Rank at round consensus exclude

new project)

Increased awareness of/knowledge about appropriate clinical behaviour (e.g. knowing when to stop and when to move forward, when to ask for help and different populations needs)

Ability to make independent clinical decisions (e.g. ability to make an urgent decision in an emergency, dealing with uncertain outcomes, evaluating risks to patients and self)

Understanding own potential to empower people

Ability to work as part of a team (e.g. understanding team group norms, perception of roles within the group, managing personal objectives within a group)

Ability to build a global network

Ability to disseminate best practice globally

Appreciation of free universal health (e.g. the NHS system of free healthcare for all, privilege and opportunity, the expectations that are placed on NHS by service users)

Improved situational awareness (i.e. understanding your environment so you can understand what to do)

Increased job satisfaction (e.g. increased motivation and morale within profession, renewed passion for work, sense of reward)

Personal satisfaction (e.g. personal achievements and challenges, new experiences, experiencing a different lifestyle, a holiday, appreciation of own life, personal fulfilment)

Can-do attitude

Ability to co-operate (e.g. willingness to see another point of view)

Appreciation of clinical governance procedures within NHS (e.g. waste disposal, audit, teamwork, education system, tests and investigations)

Appreciation of the importance of care and compassion (e.g. ability to compare compassion in both systems, empathy and fairness)

Ability to provide better care (e.g. ability to integrate primary and secondary care, to provide multicultural care, to develop most effective approaches to care and taking responsibility for providing quality of care)

Increased awareness of/knowledge about the positive impact of clinical policies and governance (e.g. understanding the benefits of a comprehensive checklist)

Increased awareness of/knowledge about ethics (i.e. experiencing ethical dilemmas, understanding the importance of ethics)

Changed perception of otherness (e.g. understanding importance of being a friendly stranger in the United Kingdom, feeling like a foreigner)

Integrity

Independence (e.g. lone working)

Ability to plan and organise (e.g. ability to set direction, improved audit skills)

Ability to make decisions (e.g. understanding who the decision is for, taking action on decision, making judgements

Ability to manage risk (e.g. manage risk in advance, evaluation of environment, understanding the clinical importance of risk management and the wider implication of poorly managed risk)

Increased patient satisfaction (e.g. staff better able to respond to UK multicultural populations, staff able more in tune with patients and more aware of individual needs of patients).

Ability to communicate non-verbally

Ability to establish communication systems (e.g. formal and informal)

Increased clinical knowledge in relation to other professions (e.g. doctors understanding nurses and vice versa, multi-disciplinary awareness)

Ability to get the most out of people (e.g. encouraging people to work together, recognise their own strengths and to take possession of their own work/projects, ability to assess the capability of others) 
Table 10 List of all outcomes and those that met consensus (those that met consensus were included in the core outcome set) (Continued)

Core outcome

Met consensus Percentage Include or Rank at round consensus exclude

Ability to manage people (e.g. able to allocate tasks and co-ordinate people, to deal with people with differing objectives, to negotiate with multiple stakeholders, to manage difficult people)

Ability to develop friendships (e.g. relationship formation skills, developing new friendships)

Ability to manage self (e.g. own expectations, self-reliance, self-management, self-assurance, reflexivity)

Changed judgement (e.g. non-judgemental attitude, changed self-judgement)

Diplomacy

Ability to find facts to solve problems

Developing redundant or bad skills/attitudes (e.g. developing non-transferable skills, bad habits, deskilling, returning with overconfidence in own ability, poorer communication skills, loss of confidence)

Financial loss (e.g. costs of getting involved, loss of earnings, pension or employment entitlement) Reduction in NHS drop outs (e.g. increased staff retention, when they volunteer and come back to $\mathrm{NHS}$ )

Ability to observe and examine patients (e.g. increased intuitive knowledge of clinical signs and clinical judgement ability to make diagnosis without investigations)

Ability to work in a professionally competent way (e.g. having wider view of profession, intellectual development, reminder of professional responsibilities, stronger work ethic)

Increased understanding of how to be a good teacher (e.g. allowing students to learn from mistakes, ability to suggest and acknowledge improvements in teaching, understanding how communication affects learning, how to target training most effectively and the importance of experiential learning)

Act as a role model (e.g. lead by example)

Influences career pathway (i.e. affects specialism choice, exploration of potential career pathways, pursuing careers in primary care, family practice, public service, sub-specialism in global health, teaching)

Ability to manage time and prioritise (e.g. ability to respond quickly in an emergency, managing immediate need vs long term need, prioritisation of limited resources)

Increased ability to change behaviour in colleagues or patients (e.g. ability to implement behaviour change and to assess the impact of healthcare systems)

Ability to manage tragedies

Reduction in staff competence (e.g. brain drain reversal: NHS loss of competent staff to overseas placements, staff unable to cope with paperwork on return)

Exposure to ethical dilemmas (e.g. expected to work outside of competency, to do clinical work, little regulation, little supervision, too much responsibility)

No recognition or accreditation upon return

Increased international reputation (of United Kingdom)

Increased international reputation of NHS (e.g. greater fulfilment of social responsibility)

Ability to verbalise knowledge (e.g. ability to verbalise core concepts and deep knowledge, ability to explain complex ideas to others)

Increased awareness of/knowledge about the importance of trust between colleagues within healthcare systems

Increased awareness of and knowledge the functioning of systems (e.g. able to identify stakeholders and change agents, understanding influencing patterns of those in power, value systems and the difficulty of questioning organisations)

Refreshment and reinvigoration (e.g. chance to take time away to become refreshed and feel reinvigorated to work upon return)

Increased awareness of/knowledge about the importance of consciously making an effort to get on with colleagues (e.g. learning colleague's names)

Ability to manage healthcare environments (e.g. ability to manage wards and staff)

Increased awareness of/knowledge about the costs of healthcare

$\begin{array}{llll}2 & 76 & + & 72 \\ 2 & 76 & + & 72 \\ 2 & 76 & + & 72 \\ 2 & & & \\ 2 & 76 & + & 72 \\ 2 & 76 & + & 72 \\ 3 & 76 & + & 72 \\ & 76 & - & 102\end{array}$

2

2

3

3

2
$+$

$+$

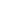

0


Table 10 List of all outcomes and those that met consensus (those that met consensus were included in the core outcome set) (Continued)

Core outcome

Met consensus Percentage Include or Rank at round consensus exclude

Ability to accept and understand failure (e.g. to continue with something that did not have

$\begin{array}{llll}2 & 71 & + & 91 \\ 2 & 71 & + & 91 \\ 2 & 71 & + & 91 \\ 2 & 70 & + & 96 \\ 4 & 70 & - & 114 \\ 3 & 70 & - & 110 \\ 2 & 70 & + & 96 \\ 3 & 70 & + & 110 \\ 2 & 70 & + & 96\end{array}$

NHS becomes a more attractive employer (e.g. an employer that offers staff the opportunity to volunteer)

Reinforced ethnic and cultural identity (e.g. understanding of own ethic and cultural identity) Ability to listen

Increased awareness of/knowledge about the importance of assessing healthcare on an individual basis (i.e. the uniqueness of each patient)

Ability to apply evidence based practice (e.g. understanding its importance (sometimes through being unable to apply it overseas), understanding how to apply it innovatively with limited resources)

Ability to give and accept praise

Ability to encourage others to take responsibility for own health

Ability to speak the host language

Ability to challenge breaches of privacy and confidentiality (e.g. ability to stand up for patients/ peoples rights if they are jeopardised, increased awareness of human rights, ability to respect regulatory standards of home and overseas regulatory bodies)

An upper hand when competing for careers

No Con

0

No Con

No Con

Escapism (e.g. freedom from bureaucracy, space outside of regular routine to clarify objectives, escape from agendas and workload, a chance to take time out of training and practice)

Improved research skills (e.g. grant application skills, research design and implementation)

Ability to present work

Ability to write reports and academic pieces

Costs to British patients (e.g. staff desensitised, staff less tolerant and patient, staff bringing tropical illnesses to the United Kingdom)

Loss of trained staff (e.g. utilisation of key staff time, financial cost of losing staff, having to find cover for staff)

Negative perceptions of NHS (e.g. NHS reputation jeopardised if a health link is badly organised)

Distracted staff (e.g. staff going on international placements coming back disengaged with UK work and pre-occupied)

Difficulty getting the job or training position that you want upon return (e.g. returning to work in a locum position, not having a permanent job upon return)

Reduced experience and exposure to UK procedures, protocols and research (e.g. NHS procedures that do not exist in host country, missing out on formal training and conferences, chronic disease management over time, health conditions that are common in the United Kingdom and not in host country, NHS protocol and updates, loss of professional networks and relationships)

Affects professional progression (e.g. lengthens training, less time to prepare for exams, time for professional readjustment upon return, career suicide, loss of partnerships)

Negative colleague perceptions (e.g. colleagues think it's a holiday, colleagues have to cover) 
Table 10 List of all outcomes and those that met consensus (those that met consensus were included in the core outcome set) (Continued)

\begin{tabular}{|c|c|c|c|c|}
\hline Core outcome & $\begin{array}{l}\text { Met consensus } \\
\text { at round }\end{array}$ & $\begin{array}{l}\text { Percentage } \\
\text { consensus }\end{array}$ & $\begin{array}{l}\text { Include or } \\
\text { exclude }\end{array}$ & Rank \\
\hline $\begin{array}{l}\text { Use of time (e.g. using annual leave to spend time on international placements, physically } \\
\text { spending time on placements that could be spent in another way) }\end{array}$ & No Con & 0 & & \\
\hline Professional revalidation issues (e.g. gaps in consultants portfolio) & No Cons & 0 & & \\
\hline Litigation (e.g. legal issues involving clinical/professional risk) & No Con & 0 & & \\
\hline $\begin{array}{l}\text { Security (e.g. exposure to aggression, violence and death, becoming a victim of } \\
\text { crime, political unrest) }\end{array}$ & No Con & 0 & & \\
\hline Carbon footprint & No Con & 0 & & \\
\hline Culture shock & No Con & 0 & & \\
\hline $\begin{array}{l}\text { Environmental and infrastructural risk (e.g. being in dangerous infrastructures and } \\
\text { environments) }\end{array}$ & No Con & 0 & & \\
\hline $\begin{array}{l}\text { Experiencing negative feelings (e.g. feeling as though imposing on UK colleagues to } \\
\text { provide cover, feeling failure, feeling out of depth, frustration, guilt and regret about death) }\end{array}$ & No Con & 0 & & \\
\hline Psychological consequences (e.g. depression, anxiety, stress, traumatisation and nervousness) & No Con & 0 & & \\
\hline Compromises of health and safety & No Con & 0 & & \\
\hline Exhaustion and burn out & No Con & 0 & & \\
\hline Loneliness (e.g. lone working, isolation, social isolation, no or few friends in host country) & No Con & 0 & & \\
\hline $\begin{array}{l}\text { Missing things at home (e.g. missing home comforts, missing life in the United Kingdom, } \\
\text { time away from family and friends) }\end{array}$ & No Con & 0 & & \\
\hline $\begin{array}{l}\text { Loss of interest in global health and international placements (e.g. not wanting to do it again, } \\
\text { negative perceptions) }\end{array}$ & No Con & 0 & & \\
\hline Socio-cultural risk (e.g. corruption, local resistance to western influence) & No Con & 0 & & \\
\hline Becoming judgemental & No Con & 0 & & \\
\hline $\begin{array}{l}\text { Negative feelings towards the NHS (e.g. questioning NHS, questioning the disposable culture } \\
\text { of NHS, having a different system to compare to NHS) }\end{array}$ & No Con & 0 & & \\
\hline Medical school more attractive to students (e.g. if allows students to go abroad) & No Con & 0 & & \\
\hline
\end{tabular}

do not know and people not being aware of what has changed for them at a particular time [39]. Nonetheless, metrics and standard indicators are useful for policy and decision-making [40], and this COS could facilitate quantification and the variables could facilitate hypothesis testing.

\section{Additional file}

Additional file 1: Systematic review search criteria. Systematic review instructions for screeners. Systematic review results: table of literature included in the review. Systematic review and meta-synthesis results: table of outcomes. Systematic review and metasynthesis results: table of variables that may affect outcomes. List of core outcomes after Delphi study: percentage of consensus, positive (include)/negative (exclusive) and the overall rank in terms of stakeholder agreement. Descriptive statistics for each statement in the Delphi across the three rounds. (DOCX $143 \mathrm{~kb}$ )

\section{Abbreviations}

CO: Core outcome; COS: Core outcome set; CPD: Continued professional development; HIC: High-income county; ILO: Intended learning outcome; LMIC: Low- and middle-income country; MOVE: MOVE Project, Measuring the outcomes of volunteering for education; NHS: National Health Service

\section{Acknowledgements}

We would like to thank Anya Ahmed, Louise Ackers, Natalie Tate, Eileen Cunningham, Hassan Osman and James Ackers-Johnson for being involved in the project and helping with the piloting of the Delphi.

We would like to thank all of the stakeholders involved in the Delphi for their significant contribution of time and effort.

The full title of the study from which this analysis was derived was Measuring the outcomes of volunteering for education (MOVE). The study was funded by Health Education England (Global Health Exchange). The research team was independent from the funding agency. The views expressed in this publication are those of the authors and not necessarily those of Health Education England or the Department of Health.

\section{Funding}

This work was supported by a project development grant from Health Education England (HEE), through the Global Health Exchange (GHE), grant ref. NURA54.

\section{Availability of data and materials}

The datasets used and/or analysed during the current study are available from the corresponding author on reasonable request.

\section{Authors' contributions}

NT participated in the design of the study; conducted the systematic review, meta-synthesis and Delphi; analysed the data; and drafted the majority of the manuscript. LBD conceived the design of the study, analysed the data and contributed significantly to the drafting of the manuscript. JC was the second reviewer in the systematic review and contributed to the drafting of the manuscript. GB provided oversight of the study design, helped recruit participants and drafted the manuscript. JH was involved in the design 
conception and drafting the manuscript. All authors participated in the coordination of the research and read and approved the final manuscript.

\section{Ethics approval and consent to participate}

The approval for the study was obtained from the Ethical Research Committee, University of Salford, and the University of Manchester Research Ethics Committee.

\section{Consent for publication}

Not applicable.

\section{Competing interests}

Professor Ged Byrne is the Director of Global Engagement for Health Education England. The other authors declare that they have no competing interests.

\section{Publisher's Note}

Springer Nature remains neutral with regard to jurisdictional claims in published maps and institutional affiliations.

\section{Author details}

${ }^{1}$ University of Nottingham, Nottingham, UK. ${ }^{2}$ Health Education England Leeds, United Kingdom. '3niversity of Manchester, Manchester, United Kingdom.

Received: 30 June 2018 Accepted: 8 November 2018 Published online: 20 December 2018

\section{References}

1. Crisp N. Mutual learning and reverse innovation--where next? Glob Health 2014;10:14. https://doi.org/10.1186/1744-8603-10-14.

2. Smith C, Pettigrew LM, Seo H-N, Dorward J. Combining general practice with international work: online survey of experiences of UK GPS. JRSM Short Rep. 2012;3:46.

3. Jones FA, Knights DP, Sinclair VF, Baraitser P. Do health partnerships with organisations in lower income countries benefit the UK partner? Glob Health. 2013;9(38). https://doi.org/10.1186/1744-8603-9-38.

4. Dean E. Tanzania changed me. Nurs Stand. 2013;27:16-7 http://www.ncbi. nlm.nih.gov/pubmed/23980965. Accessed 29 Dec 2014

5. Gilbert BJ, Miller C, Corrick F, Watson RA. Should trainee doctors use the developing world to gain clinical experience? The annual Varsity Medical Debate - London, Friday 20th January, 2012. Philos Ethics Humanit Med. 2013:8(1). https://doi.org/10.1186/1747-5341-8-1.

6. Leather AJM, Butterfield C, Peachey K, Silverman M, Sheriff RS. International health links movement expands in the United Kingdom. Int Health. 2010;2 165-71. https://doi.org/10.1016/j.inhe.2010.04.004.

7. Banerjee A. Medical electives: a chance for international health. J R Soc Med. 2010;103:6-8. https://doi.org/10.1258/jrsm.2009.090266.

8. Crisp N. Turning the world upside down : the search for global health in the twenty-first century: London: Royal Society of Medicine Press; 2010.

9. Tropical Health Education Trust. In our mutual interest. 2017. https://www. thet.org/wp-content/uploads/2017/08/In-Our-Mutual-Interest.pdf.

10. Sikka N. All aboard with impact India. Br Dent J. 2009;207:401-3. https://doi.org/10.1038/sj.bdj.2009.932

11. Young P, Smith C, Pettigrew L, Seo H-N, Blane D. International work and leadership in UK general practice. Leadersh Health Serv. 2014;27:87-103. https://doi.org/10.1108/LHS-01-2013-0003.

12. Norton D, Marks-Maran D. Developing cultural sensitivity and awareness in nursing overseas. Nurs Stand. 2014;28:39-43. https://doi.org/10.7748/ ns.28.44.39.e8417.

13. Peiying N, Goddard T, Gribble N, Pickard C. International placements increase the cultural sensitivity and competency of professional health students: quantitative and qualitative study. J Phys Ther Educ. 2012;26(61) https:/espace. curtin.edu.au/handle/20.500.11937/41580. Accessed 23 Aug 2014.

14. Thompson MJ, Huntington MK, Hunt DD, Pinsky LE, Brodie JJ. Educational effects of international health electives on U.S. and Canadian medical students and residents: a literature review. Acad Med 2003:78:342-7.

15. Dunning D, Heath C, Suls JM. Flawed self-assessment: implications for health, education, and the workplace. Psychol Sci Public Interes. 2004;5:69106. https://doi.org/10.1111/j.1529-1006.2004.00018.x
16. Dunning D, Meyerowitz JA, Holzberg AD. Ambiguity and self-evaluation: the role of idiosyncratic trait definitions in self-serving assessments of ability. J Pers Soc Psychol. 1989;57:1082-90.

17. Suls J, Lemos K, Stewart HL. Self-esteem, construal, and comparisons with the self, friends, and peers. J Pers Soc Psychol. 2002;82:252-61.

18. Health Education England. Framework 15: Health Education England Strategic Framework, 2014-2029. 2014. https:/www.hee.nhs.uk/sites/ default/files/documents/HEE\%20strategic\%20framework\%202017_1.pdf Strategic Framework 2015 Refresh Final document.pdf. Accessed 20 Jan 2016.

19. NHS England. 5 Year Forward View. 2014. https://www.england.nhs.uk/ourwork/ futurenhs/.

20. Wyler N, Green S, Boddington N, Davies C, Friedli K, Lankester T. Travel related illness in short-term volunteers from the UK to developing countries. Travel Med Infect Dis. 2012;10:172-8. https://doi.org/10.1016/j.tmaid.2012.04.002.

21. Banatvala N, Macklow-Smith A. Integrating overseas work with an NHS career. BMJ. 1997;314:2-2. https://doi.org/10.1136/bmj.314.7093.2.

22. Ackers HL, Ackers-Johnson J, Chatwin J, Tyler N. Healthcare, frugal innovation, and professional voluntarism. Cham: Springer International Publishing; 2017. https://doi.org/10.1007/978-3-319-48366-5.

23. Chatwin J, Ackers L. Organisational barriers to the facilitation of overseas volunteering and training placements in the NHS. BMC Health Serv Res. 2018;18:69. https://doi.org/10.1186/s12913-018-2853-z.

24. Baguley D, Killeen T, Wright J. International health links: an evaluation of partnerships between health-care organizations in the UK and developing countries. Trop Dr. 2006;36:149-54. https://doi.org/10.1258/004947506777978181.

25. Thompson K, Boore J, Deeny P. A comparison of an international experience for nursing students in developed and developing countries. Int J Nurs Stud. 2000;37:481-92.

26. Evans R, Dotchin C, Walker R. Maximising the value from the elective experience: post-elective workshops. Clin Teach. 2013;10:362-7. https://doi.org/10.1111/tct.12033.

27. Hannes K. Critical appraisal of qualitative research. In: Supplementary guidance for inclusion of qualitative research in Cochrane systematic reviews of interventions; 2011.

28. Benzies KM, Premji S, Hayden KA, Serrett K. State-of-the-evidence reviews: advantages and challenges of including grey literature. Worldviews EvidBased Nurs. 2006;3:55-61.

29. Thomas J, Harden A. Methods for the thematic synthesis of qualitative research in systematic reviews. BMC Med Res Methodol. 2008;8:45. https://doi.org/10.1186/1471-2288-8-45.

30. Campbell R, Pound P, Pope C, Britten N, Pill R, Morgan M, et al. Evaluating meta-ethnography: a synthesis of qualitative research on lay experiences of diabetes and diabetes care. Soc Sci Med. 2003;56:671-84 http://www.ncbi. nlm.nih.gov/pubmed/12560003. Accessed 11 Feb 2015.

31. Devane D, Begley C, Clarke M, Horey D, OBoyle C. Evaluating maternity care: a core set of outcome measures. Birth. 2007; https://www.sciencedirect. com/science/article/abs/pii/S1477893912000646. Accessed 16 Mar 2015.

32. Boers M, Brooks P, Simon LS, Strand V, Tugwell P. OMERACT: An international initiative to improve outcome measurement in rheumatology. Clin Exp Rheumatol. 2005;23(5 SUPPL):39.

33. Prinsen CAC, Vohra $S$, Rose MR, King-Jones $S$, Ishaque $S$, Bhaloo $Z$, et al. Core Outcome Measures in Effectiveness Trials (COMET) initiative: protocol for an international Delphi study to achieve consensus on how to select outcome measurement instruments for outcomes included in a "core outcome set". Trials. 2014;15:247. https://doi.org/10. 1186/1745-6215-15-247.

34. NHS Employers. Simplified knowledge and skills framework (KSF). NHS England. 2014. http://www.msg.scot.nhs.uk/wp-content/uploads/ShortGuide-to-KSF-Dimensions.pdf

35. Kiernan P, O'Dempsey T, Kwalombota K, Elliott L, Cowan L. Evaluation of effect on skills of GP trainees taking time out of programme (OOP) in developing countries. Educ Prim Care. 2014:25:78-83 http://www. ncbi.nlm.nih.gov/pubmed/24593970. Accessed 22 Jul 2015

36. Button L, Green B. The impact of international placements on nurses' personal and professional lives: literature review. J Adv. 2005; https://www. ncbi.nlm.nih.gov/pubmed/15811111. Accessed 22 Jul 2015.

37. Williams B, Morrissey B, Goenka A, Magnus D, Allen S. Global child health competencies for paediatricians. Lancet. 2014:384:1403-5. https://doi.org/10.1016/S0140-6736(14)61128-4.

38. Health Education England. Global Engagement Strategy: Strengthening the NHS workforce through global learning, vol. 2018. 
39. Guyatt G, Walter S, Norman G. Measuring change over time: assessing the usefulness of evaluative instruments. J Chronic Dis. 1987:40:171-8. https://doi.org/10.1016/0021-9681(87)90069-5.

40. Li RM, National Research Council (U.S.). Committee on Advancing Social Science Theory: The Importance of Common Metrics., National Research Council (U.S.). Committee on Social Science Evidence for Use., Workshop on Advancing Social Science Theory: The Importance of Common Metrics (2010 : National Academies (U.S.)). The importance of common metrics for advancing social science theory and research: a workshop summary. National Academies Press; 2011. https://www.nap.edu/catalog/13034/theimportance-of-common-metrics-for-advancing-social-science-theory-andresearch. Accessed 28 Sep 2018.

Ready to submit your research? Choose BMC and benefit from:

- fast, convenient online submission

- thorough peer review by experienced researchers in your field

- rapid publication on acceptance

- support for research data, including large and complex data types

- gold Open Access which fosters wider collaboration and increased citations

- maximum visibility for your research: over $100 \mathrm{M}$ website views per year

At $\mathrm{BMC}$, research is always in progress.

Learn more biomedcentral.com/submissions 